\title{
Risk, Financial Development and Firm Dynamics
}

Morais, Bernardo

Please cite paper as:
Morais, Bernardo
(2015). Risk, Financial Development and Firm Dynamics.
International Finance Discussion Papers 1134.
http://dx.doi.org/10.17016/IFDP.2015.1134

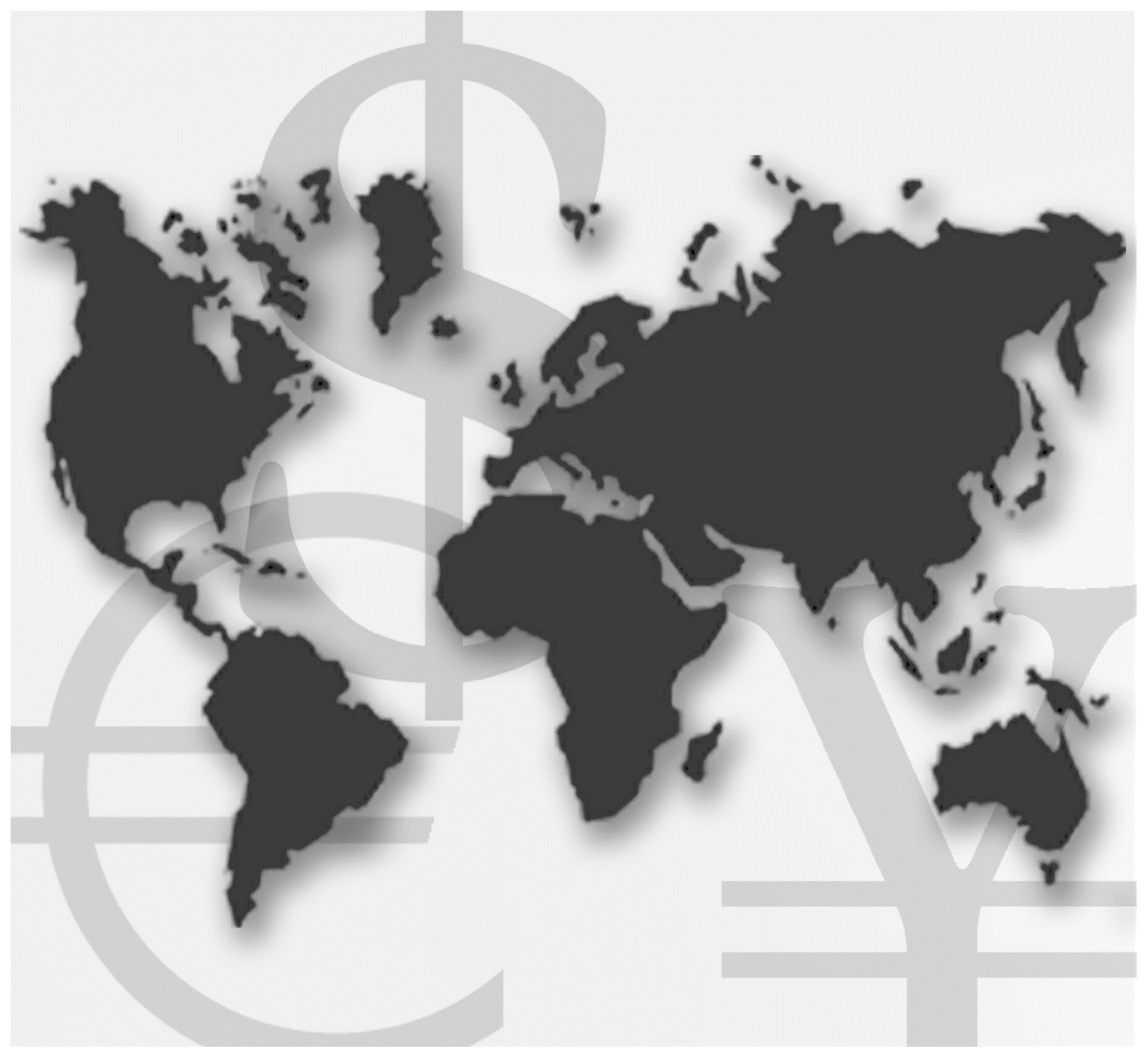

\section{International Finance Discussion Papers}

Board of Governors of the Federal Reserve System

Number 1134

May 2015 
Board of Governors of the Federal Reserve System

International Finance Discussion Papers

Number 1134

May 2015

Risk, Financial Development and Firm Dynamics

Bernardo Morais

NOTE: International Finance Discussion Papers are preliminary materials circulated to stimulate discussion and critical comment. References to International Finance Discussion Papers (other than an acknowledgment that the writer has had access to unpublished material) should be cleared with the author or authors. Recent IFDPs are available on the Web at www.federalreserve.gov/pubs/ifdp/. This paper can be downloaded without charge from the Social Science Research Network electronic library at www.ssrn.com. 


\title{
Risk, Financial Development and Firm Dynamics
}

\author{
Bernardo Morais* \\ Federal Reserve Board
}

May 2015

\begin{abstract}
I document that the average productivity of firms tends to increase, and its variance to decrease, as they age. These two facts combined suggest that managers learn to reduce their mistakes as they operate. I develop a quantitative framework mimicking these dynamics and find that young firms have substantially higher financing costs due to lower and riskier returns. In this scenario, a reduction in the financial development of an economy raises disproportionately the cost of credit of young-productive firms increasing the input misallocation within this subgroup. To test the validity of the theory, I find that the data confirms some novel predictions on a series of firm-level moments. Finally, I show that introducing these two facts allows the model to better explain the relation between financial and economic development.
\end{abstract}

Keywords: productivity, misallocation, financial frictions, learning

JEL No. O4, O11

${ }^{*}$ The views expressed in this paper do not reflect the views of the Board of Governors of the Federal Reserve System of its staff. Contact: bernardo.c.morais@frb.gov. I thank Daniel Dias, Sebastian Edwards, Paola Giuliano, Mark Grinblatt, Hugo Hopenhayn, Edward Leamer, Logan Lewis, Lee Ohanian, Claudia Ruiz, Nico Voigtlander, Romain Wacziarg, and Mark Wright, for their comments and guidance. I also thank seminar participants at the Anderson School and the Economics department at UCLA, HEC-Montreal, IESE, ITAM, FRB - Boston, FRB - BoG, University of North Carolina Chapel-Hill, UQAM, University of Western Ontario, EconCon at Princeton and SED in Brugges. Financial support from the Fundação para a Ciência e Tecnologia and Fundação Gulbenkian are grateful acknowledged. 


\section{Introduction}

The positive relation between firm age and firm productivity has been widely studied. ${ }^{1}$ Using detailed firm level data for a broad set of countries, I start by examining empirically the dynamics of revenue-productivity (TFPR) of firms as they grow older. I show that after controlling for sample selection: i) there is a positive relation between firm age and TFPR, and that ii) the volatility of the TFPR process of a firm decreases with its age. I create a model incorporating these two characteristics, which I define as Learning, and analyze quantitatively their implications. ${ }^{2}$ More concretely, I ask: If younger firms have riskier profiles and consequently face more expensive credit, how are they impacted by the level of financial development in their economy? Are young-productive firms more financially constrained and do they suffer worse factor misallocation in economies with worse financial development? If so, can this help explain the large cross-country differences in aggregate productivity?

To answer these questions I present a quantitative framework based on Midigran and Xu (2013) extended to incorporate the relation between the TFPR process and firm age. I discipline the quantitative analysis by requiring two versions of the model to mimic a series of relevant moments of the UK firm distribution. ${ }^{3}$ In the first version - defined as No-Learning - I do not require the model to replicate the above described relation between firm age and TFPR, while in the second - denoted as Learning - I do. The comparison between these two sets of simulations allows me to isolate the impact of Learning. Afterwards, and while leaving all estimated parameters unchanged, I vary the financial development of an economy to quantify its impact on firm dynamics and on aggregate income and productivity. The three main results of the paper are that under the Learning scenario: i) the model is better able to replicate a series of relevant firm-level moments not directly targeted by the calibration; ii) financial frictions constrain disproportionately more the capital accumulation of young-productive firms; and iii) financial development can help explain a larger fraction of the

\footnotetext{
${ }^{1}$ For empirical evidence on the dynamics of physical productivity (TFPQ) on aviation see Benkard (2000), on shipbuilding see Thornton and Thompson (2001) and on car manufacturing see Levitt, List and Syverson (2013). Other, more general studies relating revenue productivity and labor productivity with age, include Bahk and Gort (1993) and Jensen, McGuckin and Stiroh (2001) respectively. Similarly, Huergo and Jaumandreu (2004) and Warusawitharana (2012) document that newer establishments have higher rates of revenue-TFP growth. Finally, Foster, Haltiwanger, and Syverson (2008, 2013) decompose firm productivity into physical and revenue and report that younger firms are smaller due to demand side fundamentals.

${ }^{2}$ By defining the relation between firm age and the TFPR process, as Learning, I attempt to capture all factors influencing the TFPR process of a firm as it grows older. They include changes in supply side fundamentals such as improvements in physical productivity, as well as variation in demand-side fundamentals such as the accumulation of a customer base/reputation.

${ }^{3}$ The UK is the benchmark economy given the quality of its data and the fact that it is a financially developed economy.
} 
cross-country variation in income per capita and aggregate productivity. Finally, the model uncovers a series of novel predictions relating financial frictions with a series of firm dynamics - entry/exit, leverage and firm growth - for which I document empirical support.

The model in Jovanovic and Nyarko (1996) predicts that managers make fewer and less costly mistakes as they learn to run a project. Following this simple idea, I start this paper by documenting empirically that the expected value (variance) of the TFPR of firms increases (decreases) as firms grow older. These facts hold when using different methodologies to estimate TFPR, when testing for a broad set of countries, and controlling for sample selection. Using within firm variation, I find that the average (variance) TFPR of firms rises (falls) at a decreasing rate, during the first 20 years of a firm. I then create a quantitative framework able to replicate these two facts along with other relevant firmlevel statistics. To test the quantitative implications of this finding I use a one-sector dynamic general equilibrium model, where agents have an occupational choice - of managing a project or working for a given wage - and differ in their entrepreneurial talent and wealth. Entrepreneurial talent develops stochastically and its underlying process evolves as a project ages. More concretely, as a project grows older entrepreneurs make fewer/less costly mistakes raising expected productivity while lowering volatility. Finally, agents can transfer resources across periods using a one-period defaultable bond, with the cost of credit reflecting both the probability of default as well as the recovery rate - the proxy for financial development - in case default occurs. ${ }^{4}$

To analyze the impact of introducing the relation between firm age and productivity - i.e. Learning - I calibrate the model twice. In the first calibration - No-Learning - the simulations do not target this relation, while in the second - Learning - they do. More concretely, in this latter scenario firms can either be young or old and when young they have a probability of receiving a negative transitory shock to their productivity each period. The results of the calibration under this setting indicate that each period young firms have a 27 percent probability of suffering a 62 percent negative productivity shock. An important characteristic of the results is that under the Learning calibration the simulations can replicate (by construction) the two moments relating firm TFPR with age whereas under NoLearning they cannot. The other main difference between the two calibrations, is that the variance of productivity shocks is 32 percent lower in the Learning scenario to compensate for the productivity mistakes of young firms.

Simulations under both scenarios are fairly successful in replicating important statistics of the

\footnotetext{
${ }^{4}$ Both in the model and in the data we use the recovery rate as the main proxy of the financial development of an economy. The recovery rate measures the share of defaulting loan that is expected to be recouped by the creditor.
} 
UK economy not directly targeted by the calibrations. Nevertheless, there are three relevant statistics which are significantly better matched under Learning. The first, is the share of sales of young firms. In the Learning scenario young firms have lower average productivity and suffer larger financial constraints limiting their size. Therefore, the share of sales of firms younger than 6 years is 11 percent, as in the data, whereas in the No-Learning scenario this share is 19 percent. The second moment better matched under Learning is the leverage ratio of both young and old firms. In this setting - relative to the No-Learning one - young (old) firms are exposed to more (less) intense productivity shocks leading them to support relatively lower (higher) levels of leverage which closely mimic the UK data. Finally, and related with the previous fact, the level of debt to GDP is also better matched in the Learning scenario. Since older firms are subject to smaller productivity shocks and have higher leverage ratios, the relative level of debt to GDP is higher in this scenario and is more closely matched with the data.

As mentioned above, one of the main results of the paper is in establishing that financial constraints have a stronger impact in the resource accumulation of young and young-productive firms. In the benchmark economy, I find that the average product of capital (APK) - a proxy for borrowing constraints - is 50 percent higher for young firms and 95 percent higher for young-productive firms relative to the average firm in the simulations. In the data these values are 15 and 52 percent respectively. An additional related finding suggesting that financial constraints are stronger among young firms, is that the standard deviation of the log-APK - an indicator of capital misallocation - of young firms relative to the average firm is 15 percent higher in the simulations and 26 percent higher in the data.

After establishing that both versions of the model replicate well the UK distribution of firms, I analyze the impact that variations in the recovery rate have on a model economy. First, I show that young-productive firms are more constrained in economies with worse recovery rate. Second, I find that under the Learning scenario the model uncovers two cross-country facts on firm dynamics - leverage and firm growth - that are verified empirically. Third, I note that under the Learning framework, the model accounts for a larger fraction of the cross-countries differences in aggregate income and productivity.

The simulations under both scenarios indicate that a reduction in the recovery rate does not have a significant effect on the APK of the median firm. However they also show that reducing the recovery rate increases the APK of young and young-productive firms by around 80 percent. A significant part of these predictions are confirmed by the data. 
The model under Learning provides two new predictions relating the level of recovery rate with firm dynamics: First, selection on productivity is weaker in economies with lower recovery rate. In these economies older firms have a higher incentive to continue operating, due to a lower outside option, even when they become relatively unproductive. Therefore, in these countries there is weaker selection on productivity leading to a lower average TFPR of older firms. This result holds empirically in the cross-country sample of firms. ${ }^{5}$ I find that while in countries with high recovery rate the average TFPR of firms increases for cohorts of firms up to 20 years-old, in countries with lower recovery rate the average TFPR presents an inverted U-shape. ${ }^{6}$ Second, firms start highly leveraged and deleverage as they age. Furthermore, in economies with better recovery rate firms have higher leverage ratios and deleverage more slowly. Given their relative impatience, when agents become entrepreneurs they rely essentially on costly external debt to finance their investment, and decrease their leverage as their projects age. ${ }^{7}$ The simulations indicate that firms in economies with lower recovery rates deleverage faster due to the higher cost of debt. Empirically, I find that the average leverage ratios are essentially the same for young firms regardless of the recovery rate, and that as firms age they do indeed deleverage faster in countries with worse financial development.

Finally, I analyze the impact that financial frictions have on aggregate productivity. I find that variations in recovery rate can reduce aggregate TFP by 8 percent under the No-Learning scenario and by 20 percent under Learning. As in Buera, Kaboski and Shin (2011) the model provides a clear decomposition of the main margins affected by financial constraints. I find that under Learning oldunproductive firms employ too much capital and labor. Therefore in this scenario, and unlike in the No-Learning one, capital reallocation within age-cohorts only reduces part of the aggregate productivity losses due to misallocation.

Contribution to the Literature - The paper contributes to the vast literature relating financial with economic development in an attempt to explain the large cross-country differences in aggregate income. ${ }^{8}$ Nevertheless, the majority of this work does not replicate important features of the firm-level

\footnotetext{
${ }^{5}$ Using a different sample of countries, Hsieh and Klenow (2009) also find that older firms in poorer countries - India and Mexico - are relatively more unproductive than younger firms.

${ }^{6}$ This result is the consequence of two forces. On the one-hand, firm TFPR increases as firms age and make fewer mistakes. On the other hand, as firms are hit with permanent negative shocks, they have a relatively high incentive to continue operating given the low outside option. Under No-Learning there is a higher outside option as young firms have the same productivity process as old ones leading agents to exit when they receive a permanent negative shock.

${ }^{7}$ We find that young firms (i.e. age $\leq 6$ ) have a leverage ratio of 0.78 whereas older firms have a leverage raio of 0.65 . Huynh and Petrunia (2013), studying Canadian firms, also find that firms tend to deleverage as they grow older.

${ }^{8}$ For example, Jeong and Townsand (2007) attribute 70 percent of Thailand's growth rate between the 70s and the 90s to improvements in the financial sector. Buera, Kaboski and Shin (2011) build a two-sector model with fixed costs and show that a decrease in financial development can result in a 40 percent decrease in aggregate TFP. Amaral and Quintin (2010), Erosa and Cabrillana (2010), Castro, Clementi and MacDonald (2009), Greenwood, Sanchez and Wang (2013), and
} 
data such as the volatility of growth rates, leverage dynamics or entry/exit rates. ${ }^{9}$ This paper attempts to fill this gap by calibrating the parameters using micro moments at the firm level. The paper also contributes to the literature relating financial frictions with firm dynamics. ${ }^{10}$ In particular, it is closely related with Hennessy and Whited (2007) and Gomes and Schmid (2010) who also analyze the dynamics of firms in an environment where younger projects are impacted by higher default risk. ${ }^{11}$ In the model, I show empirically and theoretically, that their findings regarding the financial structure of firms become more acute in economies with lower financial development.

The rest of the paper is organized as follows. Section 2 describes the firm-level dataset and documents the facts around which the model is built. Section 3 introduces and characterizes the model. Section 4, presents the quantitative analysis and counterfactual experiments. Section ?? concludes suggesting further avenues for future research.

\section{Facts}

This section describes in detail the datasets used in the paper and documents empirically the two facts relating the productivity process of a firm with its age.

\subsection{Data}

\section{Firm-Level Data}

The cross-country firm level data comes from Analyze Major Database from European Sources (Amadeus). Amadeus is a comprehensive pan-European database provided by Bureau van Dijk. It is highly useful as it not only covers a large fraction of new and small firms across all industries but it also appears to be representative of the universe of firms at national level. ${ }^{12}$ The database started in 1997, and collects standardized data from 50 vendors across Europe with the local source of the data generally the office of the Registrar of Companies. Amadeus presents standardized annual data - for up to 10 years - on financial ratios, activities and ownership for approximately 5 million companies

Midrigan and $\mathrm{Xu}$ (2013) also provide quantitative assessments of the impact of financial development on aggregate income and TFP.

${ }^{9}$ An exception is Midrigan and $\mathrm{Xu}$ (2013) who require their model to match micro-moments such as the volatility of growth rates of firms or returns to capital between young and old firms.

${ }^{10}$ It includes among others, Hopenhayn (1992), , Clementi and Hopenhayn (2006) and Arellano, Bai and Zhang (2012).

${ }^{11}$ Hennessy and Whited use a structural model to calculate the costs of external financing. They find that the nature of the shocks hitting mature firms are different from small firms, with older firms having a lower variance in their shocks.

${ }^{12}$ In the appendix, I follow Arellano, Bai and Zhang (2012) and provide a comparison between the Amadeus sample and the Universe of firms present in the Eurostat. The Eurostat data - available at http://epp.eurostat.ec.europa.eu - uses the full national business registrars as data sources. Small firms are slightly underrepresented in Amadeus and its fraction varies across countries, but this variation is not correlated neither with income level nor with financial development. 
per year. It includes accounting data in standardized financial format for balance sheets, income statements, and financial ratios. The accounts are transformed into an universal format to enhance comparison across countries though the coverage of these items varies across countries. In addition to financial information, the dataset provides other information such as the age of the firm, ownership and legal status. Amadeus, assigns companies a three-digit NACE code, the European standard of industry classification, which can be used to classify firms and construct industry dummy variables.

For the empirical study and for the numerical exercises, I use the financial information presented for the 2005 to 2009 years. These consecutive years are chosen, as they are they have the most complete coverage. Since all the necessary information for this analysis is unavailable for a series of firms, I need to impose a number of restrictions in order to clean the data. ${ }^{13}$ For comparison with the vast literature using various Census of Manufacturers, I focus the analysis on firms in the manufacturing sector. Furthermore, I exclude observations of firms incorporated in the same year they were reporting or that do not provide data on assets, liabilities, sales, year of incorporation, or that provide negative sales or assets. Furthermore, I exclude countries with less than 1000 firms. ${ }^{14}$ These criteria leave us with 3 million observations in 27 countries: Bulgaria, Croatia, Czech Republic, Denmark, Estonia, Finland, France, Germany, Greece, Hungary, Iceland, Ireland, Italy, Latvia, Lithuania, the Netherlands, Norway, Portugal, Romania, Russian Federation, Serbia, Slovakia, Spain, Sweden, Ukraine and the United Kingdom.

\section{Financial Development}

In addition to Amadeus, I use data provided by the Doing Business to obtain a proxy for financial development. This dataset measures the efficiency of the insolvency process for a series of countries, following the methodology developed by Djankov, Hart, McLiesh and Shleifer (2008). Using several outcomes of the insolvency process, such as legal costs, nominal interest rate and length of the procedure, they computed the recovery rate as an indicator of investor protection. It is measured as the present value, net of all costs, recouped by the creditors of a defaulting firm. It summarizes the efficiency of the bankruptcy proceedings and is the main indicator of financial development in this paper. An advantage of using the recovery rate, is that not only it is a clean measure of investor protection but it also has a direct counterpart in the model.

In addition to the recovery rate, and to document that the empirical results carry through with other common indicators of financial development, I present two further measures proposed by King

\footnotetext{
${ }^{13}$ A more detailed explanation on the the cleaning of the data is documented in section 8.2 of the appendix.

${ }^{14}$ I exclude from this analysis Austria, Belarus, Cyprus, Liechtenstein, Luxembourg, Macedonia, Moldova, Monaco and Switzerland.
} 
and Levine (1993). The first indicator is the private credit to GDP ratio, whereas the second is the ratio of the liquid liabilities of the financial system to GDP. ${ }^{15}$ The assumption underlying these measures is that the larger the credit to private firms the more engaged financial intermediaries are in researching those same firms, in providing risk-management services and in facilitating transactions, rather than simply funneling credit to public enterprises. Figure 1, presents the three measures of financial development for each country. All indicators are highly correlated with each other. ${ }^{16}$

\subsection{Firm Productivity and Firm Age}

To document the dynamics of firm productivity, I first present the estimation method. Productivity is not observed directly and must be inferred from sales and inputs used. To calculate revenue Total Factor Productivity (TFPR) I follow Levinsohn and Petrin (2003). ${ }^{17}$ They developed a methodology for estimating the production function that deals with the endogenous response of inputs to productivity. ${ }^{18}$ This approach provides consistent estimates of the parameters for each industry and the details of the estimation procedure are documented in the appendix. After obtaining the input elasticities, I construct estimates of the firm TFPR. ${ }^{19}$

Expected value - As mentioned in the introduction, I want to understand how the average productivity of firms evolves as they age. As a first pass to the data, I plot the average TFPR - demeaned by average log TFPR - as a function of firm age, using the firm data of the four countries with the largest number of observations. ${ }^{20}$ The graphs are reported in Figure 2. The solid lines denote the

\footnotetext{
${ }^{15}$ These alternative measures were taken from the World Development Indicators.

${ }^{16}$ The correlation between recovery rate and the first and second additional indicators of financial development is 0.62 and 0.93 respectively.

${ }^{17}$ In the appendix, I show that the results obtained in this section do not qualitatively change if I estimate the revenue TFP using the input cost shares as factor elasticities.

${ }^{18}$ The endogeneity issue, driven by simultaneity, arises from the fact that productivity, which is directly unobservable by the econometrician but known by the firm, is positively correlated with input choice. This implies that an OLS estimation will yield upwardly biased coefficients. A second issue, selection bias, arises given the non-random attrition of the sample. If profitability is positively correlated with firm size, then larger firms will have a lower exit threshold on productivity. This will lead to a negative bias in the capital coefficient. To address the selection problem I must generate an exit rule. Nevertheless, and as documented in De Loecker (2007), this bias is relative small in practice, and consequently I will not control for it.

${ }^{19}$ In order to make the estimated TFPR comparable across industries we create, for both methods, a productivity index $t f p_{i, j, t}$ following Aw, Chen, \& Roberts (2001). In every industry, the productivity index is obtained by subtracting firm $i^{\prime} s$ predicted output from its actual output. This methodology insures that the productivity index is insensitive to units of measurement. The index is obtained by subtracting the productivity of a reference plant in a base year (in our case 2006) for a given industry from an individual plant's productivity measure:

$$
t f p_{i, j, t}=y_{i, j, t}-\bar{y}_{j, t}-\widehat{\beta}_{j, l}\left(l_{i, j, t}-\bar{l}_{j, t}\right)-\widehat{\beta}_{j, k}\left(k_{i, j, t}-\bar{k}_{j, t}\right)-\widehat{\beta}_{j, m}\left(m_{i, j, t}-\bar{m}_{j, t}\right)
$$

The bar over a variable indicates a mean over all firms in an industry in a base year. This measure presents the logarithmic deviation of a plant from the mean in a given sector in a base year.

${ }^{20}$ As in Levine and Warusawitharana (2013), I present the results of the regressions for the UK, our benchmark economy,
} 
average TFPR of a firm while the dashed lines indicate the associated 95th percent confidence interval. The figures indicate that in all countries the average productivity of the surviving firms tends to increase with firm age at a decreasing rate. More concretely, the average TFPR of the cohort of firms with 20 years of age is on average 20 to 85 percent higher than that of an entrant cohort. The rate of increase average TFPR for cohorts older than 20 years is positive but significantly lower than that of younger cohorts.

To study the evolution of firm TFPR more formally, I use regression techniques. First, I analyze the average TFPR of surviving firms without correcting for selection nor using firm fixed-effects. I estimate

$$
t f p_{i, t}=\beta \log a g e_{i, t}+\operatorname{Ind}_{j} \times Y e a r_{t}+\varepsilon_{i, t}
$$

where $t f p_{i, t}^{j}$ is the estimated TFPR index of firm $i$ operating in sector $j$ in year $t$. The coefficient of interest $\beta$ measures the impact of the firm log-age on the TFPR. Finally, a full set of industry-year dummies Ind $\times Y_{\text {Year }}$ are included, offering a flexible way to control for variations in productivity induced by industry-wide factors across different years. Among them, are events like weather shocks and business cycle fluctuations which tend to have a systematically different impact across sectors.

The results of this benchmark regression are reported in the columns (1) of Table $1 .{ }^{21}$ The coefficient on log-age is positive and significant in all countries. The coefficients in the four countries in the sample range from 0.01 to 0.25 . Focusing on the UK, the coefficient (0.01) indicates that as firm's age doubles the TFPR increases 1 percent on average.

To understand whether firms improve their TFPR as they age, it is more informative to use firm fixed-effects and analyze the within firm variation. The firm fixed-effect accounts for unobserved permanent components that affect firm TFPR. The results are in columns (2) and indicate that it is indeed the case that the within firm variation of TFPR of the surviving firms increases as they age. For the four countries in the sample, the coefficients range from 0.05 to 0.17 and are all significant at the 1 percent level.

However, a concern regarding the above results is the fact that the exit decision may be related with firm characteristics leaving us with sample selection bias. ${ }^{22}$ To test and correct for it I follow and for the remaining three largest economies for which our dataset has the good coverage (France, Italy and Spain). We exclude Germany, as its coverage is particularly poor since German reporting requirements are less stringent than in other European countries.

${ }^{21}$ The Amadeus dataset has no information on material expenditures for UK firms. Therefore, I calculate the TFPR for UK firms using Cobb-Douglas specification for value added.

${ }^{22}$ This concern is somewhat addressed by the inclusion of firm fixed-effects, as they imply that the variation in the growth rates is within-firm. 
Wooldridge (2002). First, I test the significance of the inverse Mills ratio obtained from a sample selection probit on the benchmark equation 1 and find that indeed there is sample selection bias. ${ }^{23}$ To correct for it, I estimate the equation

$$
t f p_{i, t}=\beta_{1} \log a g e+\alpha_{i}+\operatorname{Ind}_{j} \times \text { Year }_{t}+I M R_{t, i}+\varepsilon_{i, t}
$$

where $I M R_{t}$ is the inverse Mills ratio. The results of this regression are present in columns (3) and indicate that even after controlling for selection, firm TFPR increases as firms grow older.

Variance - In addition to the analyzing the first moment of the firm TFPR, I test Jovanovic and Nyarko's prediction that the variance of the productivity process is heteroskedastic. More concretely, I want to know whether variance tends to decrease with firm age.

As a first pass to the data, I plot in Figure 3, the standard deviation of TFPR growth for each agecohort. In all four countries in the sample, the standard deviation is decreasing and convex as firms age.

To study the relation between the standard deviation of firm growth and age more formally I follow a two-step procedure based on Castro, Clementi and MacDonald (2009). First I obtain the residual $\widehat{\varepsilon}$ after regressing the log-change of the productivity process on a series of relevant characteristics. I estimate

$$
\Delta t f p_{i, t}=\beta \log a g e_{i, t}+\alpha_{i}+\operatorname{Ind}_{j} \times \operatorname{Year}_{t}+\varepsilon_{\tau, j, t}
$$

where $\Delta t f p_{i, t}$ represents the growth rate of the $\log T F P R$ of firm $i$ between $t-1$ and $t$. I include logage as a regressor since firm age is a predictor of productivity growth. Furthermore, and as argued above, I include a firm and sector-year fixed-effects. I then use the estimated residuals $\widehat{\varepsilon}$ and proceed by estimating the equation:

$$
\ln \widehat{\varepsilon}_{i, j, \tau}^{2}=\theta_{i, t}^{\tau}+u_{i, j, t}
$$

where $\theta_{i, t}^{\tau}$ is an indicator variable of the age-group in which the firm belongs. Letting $\widehat{\theta}^{\tau}$ denote the point estimate of the dummy coefficient, $\vartheta_{\tau} \equiv \sqrt{\exp (\widehat{\theta})}$ is the estimate of the conditional standard deviation for firm TFPR in age group $\tau .^{24}$ The estimates $\vartheta_{\tau}$ of this regression are reported in

\footnotetext{
${ }^{23}$ For the first-stage probit equation I regress an exit binary indicator on firm assets, TFPR and log-age. The probit results (not shown) indicate that the probability of firm exit is negatively related with firm size, productivity and age in all 4 countries. Due to a lack of quality in the selection indicators in 2006 and 2009, for this exercise I restrict the sample to 2007 and 2008.

${ }^{24}$ This formulation results from the assumption of a particular functional form for the variance $\sigma_{j}^{2}=\sigma^{2} \exp \theta_{j}$. It is the
} 
columns (1) of Table $2 .{ }^{25}$ As posited, younger cohorts have a higher variance in their productivity growth - in all four countries in the sample - which is statistically different from the coefficients of the immediately younger/older cohorts.

As before, a concern I have in this exercise regards the selection effect. It is possible that the firms that dropped out of the sample at an early age had different characteristics regarding the productivity process, such as a larger risk-profile, which may be contaminating the results. To account for this possibility, I conduct a two-step Heckman test to deal with selection concerns where in the first step I include the inverse Mills ratio in 2. The results are reported in columns (2) of Table 2, and indicate that the results are robust when using this robustness technique.

Once established the two facts relating the TFPR process of a firm with its age, I create a general equilibrium model incorporating them.

\section{Model}

To analyze the relation between firm experience with its productivity process, I create a quantitative general equilibrium model based on Buera, Kaboski and Shin (2011) and Midrigan and Xu (2013). The model economy is populated by infinitely lived individuals, heterogeneous in their wealth and in their ability to manage a firm. Their talent follows a stochastic process which is dependent on the age of the project. Each period, agents make an occupational choice of working for a given wage or managing a firm. This occupational choice depends not only on the managing ability but also on the agents' wealth, since the cost of credit to finance project is impacted by the collateral of the entrepreneur and by the quality of financial development in the economy.

\subsection{Outline}

Environment - The economy is populated by a continuum of infinitely-lived agents of measure 1, who discount the future at rate $\beta$ and whose preferences are represented by

$$
\sum_{t=0}^{\infty} \beta^{t} \frac{C_{i, t}^{1-\zeta}}{1-\zeta}
$$

where $C_{i, t}$ is consumption of agent $i$ at time $t$ while $\zeta$ is the intertemporal elasticity of substitution.

\footnotetext{
case of multiplicative heterosckedasticity model presented by Harvey (1976).

${ }^{25}$ We have also used the Breusch-Pagan test for the null hypothesis that the conditional volatility is the same for firms in different age-groups. It rejects this hypothesis at the conventional significance level.
} 
All agents have the ability to run a project. The log of this entrepreneurial talent $z_{i, t}$ follows a continuous-state Markov process with a transition density that depends on the age $\tau$ of the project

$$
\operatorname{Pr}\left(z_{i, \tau+1, t}=z^{\prime} \mid z_{i, \tau, t}=z\right)=\pi^{\tau}\left(z^{\prime} \mid z\right)
$$

Each period, after realizing their current talent level and receiving their periodic income, agents decide how much to consume, save or borrow $B$, whether to work or manage a firm, and in the latter scenario how much to invest on assets $K .{ }^{26}$ When making their occupational choice agents take into account their ability to run a project, their savings/debt, the value of their assets, and the age of their project $\tau$. If agents opt to work they supply their unit of labor inelastically for a wage $w$. Conversely, if they choose to manage a firm they decide how much to invest and how much to borrow. Managers can only run one firm at a time, and there is no market for entrepreneurial ability.

All entrepreneurs operate in a perfectly competitive environment and have access to a production technology with decreasing returns given by:

$$
\begin{aligned}
Y_{i, t} & =Z_{i, t} K_{i, t}^{\alpha} L_{i, t}^{\gamma} \\
0 & \leq \alpha, \gamma, \alpha+\gamma<1
\end{aligned}
$$

where $Y$ is revenue, $L$ the amount of labor hired, $K$ the capital stock, and $Z$ the ability of the entrepreneur. ${ }^{27}$ The capital accumulated by the project depreciates at the rate $\delta$, and is accumulated through periodical investments $I$ such that

$$
K_{i, t+1}=(1-\delta) K_{i, t}+I_{i, t}
$$

Credit Market - Next, I describe the financial side of the model. I follow Hennessy and Whited (2007) and allow for intertemporal defaultable debt contracts $B .{ }^{28}$ All contracts with agent $i$, have a one-period maturity where the borrower receives $\frac{B_{i, t}}{R_{i, t}}$ units of capital at time $t$ with the promise to repay $B_{i, t}$ units at $t+1$. If agents save, they secure a risk-free rate $R_{f}$ determined exogenously. If they borrow, they obtain a risk-adjusted interest rate $R_{i}$ that depends on the probability of default and on

\footnotetext{
${ }^{26}$ If $B<0$ the agent has savings. As in Hennessy and Whited (2007), I do not allow for simultaneous saving and borrowing.

${ }^{27}$ The decreasing returns to scale assumption can be interpreted as arising from an environment in which monopolistic competitive firms face a constant elasticity demand function.

${ }^{28}$ Gomes and Schmidt (2010) and Arellano, Bai and Zhang (2012) also model the same type of financial contract.
} 
the recovery rate $\xi$ in case of default. More concretely, in the event of default the lender receives

$$
D_{i, t} \equiv \xi \min \left\{(1-\delta) K_{i, t}, B_{i, t}\right\}, \xi \in[0,1]
$$

where $\xi$ represents the recovery rate of the economy, $(1-\delta) K_{i, t}$ the residual value of capital and $B_{i, t}$ the outstanding debt. Conversely, the defaulting borrower appropriates

$$
T_{i, t} \equiv \varkappa \max \left\{(1-\delta) K_{i, t}-\xi B_{i, t}, \quad(1-\xi)(1-\delta) K_{i, t}\right\}
$$

where $\varkappa \in[0,1]$ is the share of the residual collateral that is appropriated by the borrower. ${ }^{29}$

I can now represent the periodic budget constraint of agent $i$ at time $t$ as

$$
C_{i, t}+I_{i, t} \leq o_{i, t}\left(Y_{i, t}-w L_{i, t}\right)+\left(1-o_{i, t}\right) w-\left(1-d_{i, t}\right)\left(B_{i, t-1}+\frac{B_{i, t}}{R_{i, t}}\right)+d_{i, t} T_{i, t}
$$

where the left-hand side represents the use of funds, while the right-hand side their origins. The variables $o$ and $d$ are binary indicators of the occupational choice and of the default decision respectively.

Recursive Problem - The timing of the model is as follows: At the beginning of each period, agents make their consumption, investment, financing and occupational choices given their capital $K$, debt $B$, ability $Z$ and project age $\tau$. After these decisions, their current ability is realized. If the agent is a worker he supplies his unit of labor, otherwise he makes his hiring decisions. Once production is complete, agents decide whether to default. Therefore, the value of agent $i$ with capital $K$, debt $B$, productivity $Z$ and age $\tau$ at time $t$ is

$$
V\left(K_{i, t}, B_{i, t}, Z_{i, t}, \tau_{i, t}\right)=\max \left\{V^{c}, V^{\text {def }}\right\}
$$

which is the maximum between the value of repaying $V^{c}$ or defaulting $V^{\text {def }}$.

The value of repaying the full amount of the debt for a worker $\left(o_{i, t}=0\right)$ or for an entrepreneur $\left(o_{i, t}=1\right)$ is

$$
\begin{aligned}
V^{c}(.) & =\max _{\{C, B, I\}} \frac{C_{i, t}^{1-\zeta}}{1-\zeta}+\beta E V\left(K_{i, t+1}, B_{i, t+1}, Z_{i, t+1}, \tau_{i, t+1} \mid .\right) \\
\text { s.t. } C_{i, t}+I_{i, t} & \leq o_{i, t}\left(Y_{i, t}-w L_{i, t}\right)+\left(1-o_{i, t}\right) w-B_{i, t-1}+\frac{B_{i, t}}{R_{i, t}} \\
K_{i, t+1} & =(1-\delta) K_{i, t}+I_{i, t}
\end{aligned}
$$

\footnotetext{
${ }^{29}$ When $\varkappa<1$, part of the renegotiation process results in losses of capital for the economy.
} 
whereas the value of default is

$$
\begin{aligned}
V_{t}^{\text {def }}(.)= & \max _{\{d, B, i, l\}} \frac{C_{i, t}^{1-\zeta}}{1-\zeta}+\beta E V\left(I_{i, t}, B_{j, t+1}, Z_{j, t+1}, \tau_{j, t+1} \mid .\right) \\
& \text { s.t. } C_{i, t}+I_{i, t} \leq o_{i, t}\left(Y_{i, t}-w L_{i, t}\right)+\left(1-o_{i, t}\right) w+T_{i, t}
\end{aligned}
$$

Equilibrium - The framework is designed for the purpose of studying a stationary competitive equilibrium. In this equilibrium, some firms enter and expand, whereas others contract and exit. Despite all these individual changes, aggregate variables remain constant through time. For each debt contract the interest rate $R_{i}$ that allow creditors to break even in expected value is such that

$$
R_{f}=\left(1-\pi_{i}\right) R_{i, t}+\pi_{i} R_{i, t} \xi \min \left\{\frac{(1-\delta) K_{i, t}}{B_{i, t}}, 1\right\}
$$

where the left-hand side represents the risk-free rate $R_{f}$, while the right-hand side represents the expected repayment rate of a debtor with default probability $\pi_{i, t}$ and collateral $K_{i, t}$. Therefore, the risk adjusted interest rate is

$$
R_{i, t}=\frac{R_{f}}{1-\pi_{i, t}\left(1-\xi \min \left\{\frac{(1-\delta) K_{i, t}}{B_{i, t}}, 1\right\}\right)}
$$

This lending rate depends on the probability of default and on the recovery rate. ${ }^{30}$

A stationary competitive equilibrium for this economy consists of: an invariant distribution of wealth, capital and talent $G(B, K, Z)$, policy functions of agents $C(K, B, z, \tau), I(K, B, z, \tau), B(K, B, z, \tau)$, $l(K, B, z, \tau)$ loan contracts offered by creditors $R_{i, t}(K, B, z, \tau)$ and prices $w, R_{f}$ such that:

1. Given the schedule of loan contracts offered, the policy and value functions of agents satisfy their optimization problem

2. Loan contracts reflect the firm's default probabilities such that all financial intermediaries make zero profits in expectation on all contracts

\footnotetext{
${ }^{30}$ To provide some intuition to the expression above, assume that $\frac{(1-\delta) K_{i, t}}{B_{i, t}} \geq 1 \forall\{K, B\}$. In this case, condition 7 becomes

implying that interest rate is

$$
R_{f}=R_{i, t}\left(1-\pi_{i, t}\right)+R_{i, t} \pi_{i, t} \xi
$$

$$
R_{i, t}=\frac{R_{f}}{1-\pi_{i, t}(1-\xi)}
$$

where it is clear that interest rate is positively related with the probability of default, and negatively related with the recovery rate.
} 
3. The joint distribution of wealth and talent are stationary

4. Labor market clears

\section{Quantitative Analysis}

In this section, I assess quantitatively the implications of the model. In a scenario where the productivity process of firms is related with their age, I analyze the importance of financial development in explaining the large cross-country differences in firm dynamics and aggregate outcomes in scenarios with and without Learning .

\subsection{Calibration}

A common strategy in quantitative evaluations of the effect of financial frictions is to replicate a relatively undistorted economy, and then use these parameters to evaluate the variations in financial development. Therefore, I calibrate the exogenous parameters so that the benchmark economy matches key aspects of UK firm data.

Before the parameterization, I must specify a functional form for the productivity process as well as the mechanism relating firm age with the productivity process. I assume that in the benchmark scenario where there is no relation between the firm age and TFPR - defined as No-Learning - the log productivity of a the firm $z_{i, t}^{n l}$ is the sum of two components:

$$
z_{i, t}^{n l}=A_{i, t}^{\tau}+\varepsilon_{i, t}
$$

where $A$ is a more persistent component while $\varepsilon$ is a periodic shock. I think of $A$ as capturing the fundamental quality of an idea for a project and assume that $\exp \left(A_{i}\right)$ is drawn from a Pareto distribution $\operatorname{Pr}\left(\exp \left(A_{i}\right)<x\right)=1-x^{-\mu}$. The shape of the Pareto distribution is given by $\mu$ and will be estimated. Although this productivity component is persistent, each period agents have a probability $\kappa$ drawing a new independent idea making them forgo the old one. ${ }^{31}$

The second component of productivity $\varepsilon$ follows an $\mathrm{AR}(1)$ process

$$
\varepsilon_{i, t}=\rho \varepsilon_{i, t-1}+\nu_{i, t}
$$

\footnotetext{
${ }^{31}$ The inclusion of the somewhat permanent component $A$, allows the model to replicate the large autocorrelation of sales verified in the data. The idea/death shock is common in the literature and allows the model to replicate the fact that large firms exit the market.
} 
where shocks $\nu$ are drawn from a normal distribution

$$
\nu_{i, t} \sim N\left(0, \sigma_{\nu}^{2}\right)
$$

To capture the relation between firm age and TFPR, I assume that firms have a periodic productivity adjustment $s^{\tau}$ with a probability $p^{\tau}$ which is dependent on firm age/experience $\tau$. The $\log$ productivity of the project $z_{i, t}^{l}$ in this Learning scenario is

$$
\begin{aligned}
& z_{i, t}^{l}=z_{i, t}^{n l}+s^{\tau}
\end{aligned}
$$

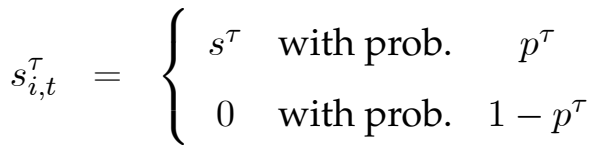

Furthermore, and to reduce the age $\tau$ state space, I assume that projects can be either young or mature, and that mature projects have no adjustments $\left(s_{i, t}^{m}=0\right)$. In the period in which workers change their occupation and become entrepreneurs the project is considered young. Thereafter, and if the agent remains an entrepreneur, projects have a periodic probability $\pi^{\tau}$ of becoming mature. Once the project is mature, it remains so as long as the agent continues an entrepreneur.

To measure the impact of the productivity/age relation I calibrate Learning and No-Learning economies. From the 11 parameters, five are set to standard values in the literature. As Midrigan and Xu (2013), I set: the coefficient of risk-aversion $\zeta$ to 1 , the subjective discount rate $\beta$ to 0.92 , the riskless rate $R_{f}$ to 0.04 , the one-year depreciation rate $\delta$ to 0.06 . the curvature of the production function $\alpha+\gamma$ to 0.85 and the serial correlation parameter $\rho$ to 0.35 .

I am thus left with six (four) parameters in the Learning (No-Learning) scenario which are specific to the study $\{\mu, \varkappa, \kappa, \sigma, s, p\}$ and I calibrate them to match six (four) relevant moments of the UK data: The employment share of the top decile of firms, the default rate of small and medium firms, the exit rate of mature firms, the standard deviation of the log value-added of mature (all) firms, and in the Learning scenario, the standard deviation of log value-added of young firms

In the model, and for identification purposes, all parameters indirectly impact all moments in a non-linear fashion. Nevertheless, some moments are impacted more strongly by certain parameters. Therefore, I calibrate the shape of the Pareto distribution $\mu$ to match the employment share of the top decile of firms. The residual recovery share $\varkappa$ allows the simulations to replicate the default rate of small and medium firms. The probability of receiving a new idea $\kappa$ aims at replicating the empirical exit rate of mature firms $($ age $>10)$. The variance of the productivity process in the Learning (No- 
Learning) scenario is set so that the model replicates the standard deviation of sales growth of mature (all) firms.

The estimated parameters and target moments are reported in Tables 3 and 4 respectively. ${ }^{32}$ Overall, both calibrations are successful in matching the target moments in the data. The model captures well the distributions of income and firm size, as well as the standard deviation of output growth rates and the productivity of old relative to young firms.

As expected, in the Learning calibration both $p>0$ and $s<0$ implying that young firms do make costly productivity mistakes. I also note that the No-Learning calibration cannot capture neither the decrease in the volatility of sales as firms age, nor the increase in average firm productivity of older firms.

\subsection{Learning vs. No-Learning}

Before comparing the empirical results with the model predictions it is convenient to understand its basic mechanics. In Figure 4, I exhibit a series of policy decisions in an economy with the UK recovery rate $\left(\xi_{U K}=0.85\right)$ in scenarios with and without Learning. ${ }^{33}$ The first panel, displays the behavior of the ratio of investment to assets. Investment rate is similar in the incumbent and in the No-Learning scenarios, and is significantly lower for an entrant firm. To understand if this is indicative of financial constraints, I follow Midrigan and Xu (2013), and graph in the second panel the average product of capital (APK - ratio of sales to assets). As expected, the APK of an entrant firm is higher than that of an incumbent suggesting stronger constraints. In the fourth panel, I depict the leverage ratio. As expected, entrant firms have the lowest leverage ratios due to their higher cost of external finance.

Figure 5, contrasts the dynamics of a firm in its first ten years in scenarios under both Learning/NoLearning. ${ }^{34}$ The first panel, exhibits the evolution of firm assets. In the No-Learning scenario firm growth is much faster. A firm with four years is almost three times larger in this scenario and is almost twice as large when it reaches ten years. The second panel suggests that the main reason for these size differences is that firm debt can be up to five times larger in the No-Learning scenario. In the third panel, I exhibit the leverage ratios for the two scenarios. In both scenarios, firms start with

\footnotetext{
${ }^{32}$ The majority of moments were obtained using the information on UK firms drawn from Amadeus. The exceptions are: top 5 percent income share, average firm employment and firm exit rate. For the income share of the top 5 percent we use information in Alvaredo, Atkinson, Piketty and Saez (2013), while for the firm exit rate and average firm employment we used the UK industrial demographic statistics from the OECD Structural Statistics for Industry and Services for 2006.

${ }^{33}$ In both scenarios we depict the choices of a talented entrepreneur with the same amount of debt for various levels of assets. Furthermore, we assume that the entrant entrepreneur is making no mistakes.

${ }^{34}$ Under both scenarios, firms have the same (high) productivity throughout the 10 years. Furthermore, the firm is kept an entrant in the Learning simulation.
} 
similar and high leverage. As firms grow older this leverage ratio decreases in both scenarios, albeit at a slightly faster pace in the Learning scenario. Nevertheless, this faster pace is reversed around the 10th year (not shown) and the leverage ratios become larger in the Learning scenario due to the lower variance in productivity shocks. Finally, in the fourth panel, I depict the APK. As before, APK is larger in the Learning scenario throughout the lifecycle of the firm especially for younger firms suggesting higher financial constraints.

To analyze the relative success of both versions of the model in replicating the UK distribution of firms, I report in Table 5 additional empirical and theoretical moments not directly targeted by the calibration. For now, I focus in both Learning/No-Learning scenarios with a $R R_{U K}=0.85$. Both Figures 4 and 5, suggested that productivity shocks under Learning increased financial constraints, forcing firms to start smaller. The results reported in Table 5 support this idea, since the share of sales of young firms ( $\leq 5$ years) is 20 percent in the No-Learning scenario and only 12 percent under Learning, which closely matches the 11 percent in the UK data. Regarding the use of debt, both versions of the model are able to mimic its general dynamics. In the data, the ratio of aggregate debt to total assets for young firms is 0.81 and decreases for older firms to 0.72 . Both versions of the model replicate the decrease of leverage as firms age, but the dynamics under Learning are better able to mimic the general pattern, especially for the older cohorts. As discussed above, the cost of debt is strongly impacted by the variance of shocks. ${ }^{35}$ This implies that while the average leverage ratios for young firms are a touch lower in the Learning scenario $\left(\operatorname{Lev}_{N o-L r n}^{y n g}=0.83\right.$ vs. $\left.L e v_{L r n}^{y n g}=0.82\right)$ for older firms this result is reversed $\left(L e v_{N o-L r n}^{o l d}=0.48\right.$ vs. $\left.L e v_{L r n}^{o l d}=0.59\right)$.

\subsection{Financial Development and Firm Dynamics}

In this section, and focusing on the Learning scenario, I investigate the impact of recovery rate, the proxy for financial development, on firm dynamics and aggregate outcomes. First, and for illustration purposes, I present a series of exhibits representing the decision rules in scenarios with three different levels of recovery rate. ${ }^{36}$ In Figure 6, I illustrate the evolution of a series of firm characteristics - assets, debt, leverage and APK - during its first 10 years, while keeping the productivity constant. As expected, in the first two panels firms in economies with higher recovery rate start significantly larger, since they are able to access cheaper debt. In the third panel, I graph the evolution of

\footnotetext{
${ }^{35}$ In the Learning scenario younger (older) firms have a higher (lower) variance in their productivity shocks relative to the No Learning version.

${ }^{36} \mathrm{The}$ three recovery rates chosen were $\{0,0.25,0.85\}$. The first level mimcks an economy without investor protection, the second recovery rate is the median value of the lowest quintile and corresponds to the Russian recovery rate, while the final recovery rate is that of the UK, the benchmark economy.
} 
firm leverage. In the scenario with highest recovery rate (solid line) leverage ratio starts at 1 , whereas in the scenario with the Russian recovery rate (dotted line) firms start with a leverage ratio of 0.5 . In all scenarios, firms deleverage as they age. An important consequence of the differences in the access to finance is illustrated in the last panel. Using the APK as a proxy of financial constraints, I note that the ratio $\frac{A P K_{\xi=0}}{A P K_{\xi=0.85}}$ for entrant firms is 4 and it only converges to 1 when firms are older than 12 years-old (not shown). Therefore, Figure 6 suggests that financial constraints are dependent on the recovery rate and have the strongest effect on young firms under Learning.

\section{Variations in Recovery Rate under Learning and No-Learning}

As a first pass on the impact of recovery rates under both Learning/No-Learning scenarios, I extend Tables 4 and 5 to include moments in economies with low financial development (i.e. $\xi=0.25$ ). The four main messages are: i) employment concentration decreases with financial development, especially in the Learning scenario. While under high financial development in both Learning/No-Learning scenarios, the top-10 percent of firms employed 69 percent of workers, the concentration is substantially higher in the Learning scenario under low financial development (0.86 vs. 0.71). This result is partly driven by the fact that rich-productive entrepreneurs increase their scale due to the lower competition for workers from young firms. For example, under low financial development in the Learning scenario, young firms with less than five years account for only three percent of the share of sales; ii) there are lower entry/exit rates in the Learning scenario under low financial development. In this scenario young firms (i.e. $<10$ years) represent less than 10 percent of total firms, whereas in the Learning scenario they represent more than 60 percent. This occurs because workers only become entrepreneurs in those rare instances where they have a highly productive idea. Therefore, in this scenario young firms are scarce but they start relatively large. ${ }^{37}$ Consequently, the lack of competition from entrants under low financial development in the Learning scenario leads to low exit rates of old firms. ${ }^{38}$ Rich entrepreneurs, even when they suffer a bad and permanent productivity shock, tend to continue operating due to the low wages prevalent in the economy; iii) the relative productivity of older firms is significantly lower in the Learning scenario with low financial development. This result is directly related with the previous point. In this scenario, rich but unproductive entrepreneurs are not selected out and continue operating. In fact, and under the Learning scenario, older firms in the economy with high financial development benefit from the reduction in mistakes

\footnotetext{
${ }^{37}$ The average size of a firm with less than five years is of 33 employees. In the No-Learning scenario the average number of employees is 5 .

${ }^{38}$ For example, under low financial development the exit rate is of only 1 percent under Learning, compared with 23 percent under No-Learning.
} 
and are on average 11 percent more productive. However in the No-Learning scenario, older firms are on average 32 percent less productive, since entrepreneurs hit by bad-permanent shocks do not have the incentives to exit; and finally iv) access to external financing is highly dependent on financial development. In both Learning/No-Learning scenarios, in economies with high recovery rate both interest rates are 7 p.p. lower on average while the leverage ratios are on average three times higher. Therefore variations in the recovery rate have large real effect on the financing of firms.

\subsubsection{Firm Dynamics}

To further attest for the relative importance of the relation between firm TFPR and firm age, in this section, I compare the cross-country behavior of other firm dynamics (e.g. TFPR and leverage) in economies with varying levels of recovery rate in scenarios with and without Learning. I start by comparing graphically the predictions of the simulated model with the data. Afterwards I test more formally the results, both in the empirical and simulated data, by estimating regressions of the type

$$
x_{i, t}=\beta_{0}+\beta_{1} \log a g e_{i, t}+\beta_{2} \log a g e_{i, t} \times F D_{c}+\text { ind } \times \text { year } \times \text { ctry }+v_{i, t}
$$

where $x$ is a firm-level variable (e.g. leverage) of firm $i$, on year $t$. The explanatory variables are $a g e_{i, t}$ which indicate the age in years of firm $i$ at time $t$, while $F D_{c}$ corresponds to a measure of financial development. ${ }^{39}$ Finally, I also include a series of dummies ind $\times$ year $\times$ ctry to control for industry, year and country fixed-effects. The industry fixed-effects, control for all industry features such as capital intensity and tradability that may induce different firm behavior across industries. The year fixed-effects control all year specific characteristics such as the phase of the business cycle in an economy. Finally, the country fixed-effects, control for all country characteristics such as the level of financial development, accounting practices and institutional quality that may impact firm policies.

\section{Evolution of TFPR}

In this paper, I am interested in the relation between the TFPR of firms and their age. As a first pass into the predictions of the model I display in Figure 7 the relation between firm age and the average log TFPR in the economies with high/low recovery rate. ${ }^{40}$

\footnotetext{
${ }^{39}$ In our benchmark regressions we use the recovery rate as an indicator of financial development. In the appendix, and for robustness purposes, we run all regressions using alternative indicators of financial development.

${ }^{40}$ Due the lack of materials data for a large fraction of firms in lower income countries, the measure of TFPR used in this section follows Syverson (2004) and uses expenditures shares to calculate the elasticities of the factors of production. Details of this approach are provided in the appendix.
} 
In the first panel, I graph the average TFPR across age-cohorts in two simulated economies with varying levels of recovery rate $(R R=\{0.25,0.85\})$ under No-Learning. In this framework, the selection on productivity is similar under the two recovery rates and average TFPR remains relatively unchanged across the age-cohorts. In the second panel, I present the dynamics of firm TFPR under the Learning scenario. As expected, given the structure of productivity introduced, the average TFPR is higher for older cohorts in both economies as firms reduce their mistakes with age. Nevertheless, while the increase in average TFPR is concave and increasing in the economy with high RR, for the economy with low RR the average TFPR presents an inverse U-shape. The main reason for this difference is the lower selection on productivity in countries with worse RR. This occurs when wealthy entrepreneurs are hit with a negative permanent productivity shock and prefer to continue operating benefiting from the relatively low wages in the economy. In the third panel, I present the empirical comparison. In the data, the average TFPR increases with firm age in the high RR countries and the average TFPR of the 15-year cohort is 20 percent higher than that of an entrant cohort. Interestingly however, the behavior of the average TFPR in countries with lower RR has an inverse U-shape. This mimics very closely the behavior of firms under Learning, rendering support to the above mentioned mechanism. In Figure 8, I present the same relation as in Figure 2. However, instead of using four countries with high recovery rate, I follow the evolution of average TFPR in four countries with low levels of recovery rate. ${ }^{41}$ As predicted from Figure 7, the evolution of TFPR for these countries presents a much weaker growth, and in many cases a decrease, than in the richer countries. According to the model under Learning, this is driven by the poorer selection on productivity. I then run the more formal equation 10 using the empirical and simulated data and the results are in Table 7 . They confirm the analysis from the graphs. The average TFPR increases with firm age with an elasticity around 0.05 and this effect is significantly stronger in economies with higher recovery rate.

\section{Dispersion of TFPR}

The main premise of this paper is that the variance of firm productivity decreases as firms grow older due to Learning. In the model, I introduced this concept by assuming that as firms aged they reduced the frequency and magnitude of their mistakes. In Figure 9, I compare the standard deviation of TFPR growth across age-cohorts both in the simulated model and in the data. ${ }^{42}$ In the first two panels, I display the results of the simulations. Under No-Learning the TFPR dispersion tends to

\footnotetext{
${ }^{41}$ The countries are: Ukraine, Romania, Czech Republic and Hungary. These countries were chosen as they have low levels of recovery rate and have a large number of firms (i.e. >1000) across all 15 age-cohorts. I also limited the analysis to the age-cohorts up to 15 years, to truncate those firms created during the communist era.

${ }^{42}$ The standard deviation of TFPR is measured as the standard deviation of the log-TFPR growth rate for each age-cohort.
} 
increase slightly. Conversely, under Learning the TFPR dispersion decreases as firms age and reduce their mistakes. The reason for this difference is that under Learning as firms age and become mature the variance of their shocks decreases. Conversely under the No-Learning scenario, where variance of the productivity process is independent of age, the dispersion in TFPR increases a touch with age since larger firms which are hit by a slightly negative productivity shock may continue operating. In the third panel, I present the empirical results of the evolution of the standard deviation of TFPR for all firms in the sample. In both sets of countries - with high and low RR - the standard deviation of the log growth of firm TFPR decreases with older cohorts. Again, these results are supportive of the productivity process in the Learning scenario.

Again, the results from the regressions in Table 7 confirm the above analysis. The empirical regression indicates that the elasticity between age and the standard deviation of TFP is negative and between -0.06 and -0.25 .

\section{Leverage}

Since the focus is on the impact of financial constraints on firm behavior, I examine how leverage - ratio of total liabilities to total assets - varies with different levels of recovery rate. As before, I use the model to obtain a first pass into the predictions of the model. In the first two panels of Figure 10 I display the average leverage ratio across age cohorts in two economies with varying recovery rates under both Learning and No-Learning. Both scenarios paint a similar picture. Entrepreneurs start a project with relatively high leverage which decreases as firms age. Furthermore, and even though firms start with similar leverage ratios across economies they tend deleverage faster under low RR due to the higher cost of debt. An important difference between the Learning/No-Learning scenarios, and due to the lower risk of older firms under Learning, leverage tend to decrease more slowly especially in economies with better recovery rate. The third panel, again provides the empirical comparison. Empirically, the behavior of the leverage ratio is relatively similar to the Learning simulation. 43

The results from the regression are reported in Table 7. They confirm that the elasticity of age to leverage is negative and around -0.05 . Nevertheless, and unlike the model results, the crossderivative between $R R$ and log-age is slightly negative implying that firms in economies with better RR deleverage faster. ${ }^{44}$

\footnotetext{
${ }^{43}$ These results are in line with existing findings in the literature. Huynh and Petrunia, using a dataset of Canadian manufacturing firms, find that that the leverage ratio of the surviving firms decreases with firm age.

${ }^{44}$ In Table 9 this result is reversed when we use alternative indicators of financial development.
} 


\subsection{Financial Development and Aggregate Productivity}

In this section, I analyze the impact that recovery rate has on aggregate productivity and factor misallocation, under Learning and No-Learning scenarios.

\section{Aggregate Productivity}

One of the most interesting features of the model, is that it allows us to quantify the impact Learning has on the relationship between financial development and aggregate productivity. ${ }^{45}$ In this section, I vary the recovery rate and calculate the corresponding aggregate TFP under both Learning/NoLearning scenarios. In Figure 11, I report the effect of these financial frictions on aggregate TFP and on that of young and old firms. ${ }^{46}$ As in the data, the cross-country differences in income per capita (not shown) are mainly driven by variation in aggregate TFP. Variation in RR can reduce aggregate TFP by 8 percent under No-Learning and 16 percent under Learning. Therefore, introducing Learning in a standard model with firm heterogeneity doubles the impact of financial development. Delving deeper into this result, in the second and third panels I divide the sample into old and young firms. In the second panel, I present the aggregate TFP of firms younger than six-years. In the No-Learning scenario the aggregate TFP of young firms increases slightly with level of recovery rate. ${ }^{47}$ However, under Learning the aggregate TFP actually decreases with recovery rate. This result is driven by the fact that under Learning and in economies with low recovery rate, workers - who have low access to external financing - only become entrepreneurs in those rare instances where they have an extremely productive project. In the third panel, I do the same exercise but for the older firms. In this case the result under Learning is reverted, with the recovery rate being highly related with the aggregate TFP. In this scenario, an increase in recovery rate leads to a rise in aggregate TFP of around 13 percent. As noted in the next section, this result is driven by the low exit rates of large-unproductive entrepreneurs. Finally, in the last panel, I graph the relative aggregate TFP of old to young firms. Whereas the ratio is constant and close to one under No-Learning, it is highly increasing with the recovery rate under Learning for the above mentioned reasons. Furthermore, and given that the ratio is lower than one, it implies that under Learning the aggregate TFP of old firms is significantly lower than that of younger ones. To compare the simulations with the data, in Figure 12 I replicate the last panel using the firm level in Amadeus. ${ }^{48}$ Interestingly, and as predicted by the model in the Learning scenario,

\footnotetext{
${ }^{45}$ To calculate aggregate TFP, I use the data provided by PWT 6.1. TFP is $Y K^{-1 / 3} L^{-2 / 3}$, where $Y$ is GDP-PPP, $K$ is the capital stock, and $L$ is the number of workers. I calculate the capital stock using the perpetual inventory method at a $6 \%$ depreciation rate.

${ }^{46}$ For each scenario, I ran simulations for 12 different levels of recovery rate.

${ }^{47}$ In the next sections I show that this is driven by variations in input misallocation.

${ }^{48}$ For data consistency, I excluded firms that did not have information on assets, materials, employment and sales. Fur-
} 
the aggregate TFP of old relative to young firms is increasing in RR due to the reduction in productivity mistakes. This effect is less prevalent in economies with lower RR due to weaker selection on productivity.

\section{Firm Turnover}

To further analyze the above results, in Figure 13 I exhibit a series of graphs whose main message is: in economies with low financial development under the Learning scenario, rich-unproductive entrepreneurs do not exit the market, crowding-out younger more productive, albeit poorer, entrepreneurs who find it costly to obtain financing. In the first panel, I exhibit the share of production of young firms with less than six years. In both scenarios, this share increases with RR, however the level is substantially lower under Learning by around 10 percentage points. In fact, when $\xi=0$, this share is of only 2.5 percent, compared with 19 percent when $\xi=1$. The second and third panels, display the fraction of young firms and the exit rate of old firms respectively. Not surprisingly, both panels paint a similar picture. In economies with low RR under Learning, both the share of young firms and the exit rate of older ones are extremely low. Around 5 and 0.5 percent respectively. Conversely, under No-Learning there is more turnover and it is roughly constant across all levels of financial development, as the exit rate of older firms is roughly determined by the frequency of the permanent shock.

\section{Capital Misallocation}

As Hsieh and Klenow (2009) noted, dispersion in marginal productivity of capital (MPK) is an important source of misallocation leading to losses of aggregate TFP and income per capita. ${ }^{49} \mathrm{Com}-$ paring simulations and in the model, I present in Table 6, the theoretical and empirical moments of the APK.

In Panel A of Table 6, I present the APK for a series of simulations in economies with varying levels of financial development. In economies with lower recovery rate, not only is the APK higher on average for all firms, but it is especially higher for young and productive firms. In addition to the average APK, the model simulations indicate that firms in economies with lower recovery rate have a higher dispersion of average productivity of capital consistent with higher input misallocation.

In Panel B, I present the average APK for firms in the 27 countries in the sample. I divided the countries into two groups depending on their recovery rate. I ended up with 15 High RR and 12

thermore, I excluded countries with information on fewer than 5000 firms. These conditions led to the exclusion of nine countries, notably the UK which does not have data on materials used.

${ }^{49}$ In our analysis we focus on the average product of capital. In a one-sector model under Cobb-Douglas the two concepts are proportional. 
Low $R R$ countries. ${ }^{50}$ As predicted by the model, the average APK is higher, 17 percent, in economies with worse financial development and it is also higher for younger firms. Furthermore, and also in accordance with the model, the average APK of younger firms is relatively larger in countries with lower RR, 18 percent vs. 10 percent. Finally, the model simulations are consistent with youngproductive firms being more constrained in economies with low RR. Again, this fact holds in the data. The APK of young-productive firms in countries with low RR is 71 percent higher relative to all firms in those countries, and it is "only" 51 percent in countries with high RR. I also follow Buera, Kaboski and Shin (2011) in using the standard deviation of the $\log (\mathrm{APK})$ of firms as an additional measure of factor misallocation. As in the model, in the data there is a higher dispersion for younger firms, 1.38, than for older firms, 1.10 .

\section{Factor Misallocation and Output Loss}

To understand the source of the cross-country differences in aggregate productivity, I follow Buera, Kaboski and Shin (2011) and decompose factor misallocation within and across age-groups under scenarios of Learning and No-Learning. ${ }^{51}$ First, I estimate the impact of the capital and labor misallocation within age-cohorts by reallocating these factors of production across firms within the same cohort so that the marginal productivity of capital (MPK) and labor (MPL) are equalized across firms within that cohort. In the second step, I calculate the misallocation of factors of production across age-groups, by reallocating the factors of production to equalize both MPK and MPL across all firms. The results of this exercise are reported in Figure 14. In the first (second) panel I report the results under No-Learning (Learning). The main conclusions to draw from this exercise are: i) factor misallocations are decreasing with the RR and higher in the Learning scenario. ii) in both scenarios the factor misallocation within age-cohorts accounts for all aggregate TFP losses in economies with high levels of RR, whereas in economies with low RR it accounts for around 75 percent of the losses with the remaining 25 percent due to misallocation across age-groups. This is equivalent to say that transfers of factors of production from old to young firms would improve aggregate TFP by 5 percent in these economies. iii) Under the No-Learning scenario, the majority of the factor misallocation is within age-groups. Under this scenario there would be no improvements in aggregate TFP by transferring factors of production across age-groups.

\footnotetext{
${ }^{50}$ We divided countries into high (low) recovery rate if their value was above (below) 0.4. The results are not impacted qualitatively if we had chosen either 0.3 or 0.5 as alternative cutoff values.

${ }^{51}$ I split firms into young and old using 8-years as a threshold which splits the firms into two groups with roughly the same number of observations.
} 


\section{Conclusion}

I have documented two empirical regularities regarding the dynamics of the TFPR of firms as they age. I found, for a broad set of countries, that the TFPR tends to increase as firms age while the volatility of the productivity process decreases. I created a quantitative framework to analyze the importance of this mechanism - which I defined as Learning - and noted that by including it allowed the model to better match some of its empirical moments such as the dynamics of leverage or the share of production of young firms. Understanding the mechanisms driving this Learning process, as well as the factors determining its dynamics, is a possible avenue for future research.

\section{References}

\section{References}

[1] Alvaredo, F., A. Atkinson, T. Piketty and E. Saez (2013) - "The Top 1 Percent in International and Historical Perspective", Journal of Economic Perspectives, 27: 3-20.

[2] Amaral, P., and E. Quintin (2010) - "Limited Enforcement, Financial Intermediation and Economic Development: A Quantitative Assessment", International Economic Review, 51: 785-811.

[3] Arellano, C., Y. Bai, and J. Zhang (2012) - "Firm Dynamics and Financial Development", Journal of Monetary Economics, 59: 533-549.

[4] Aw B., X. Chen and M. Roberts (2001) - "Firm-Level Evidence on Productivity Differentials and Turnover in Taiwanese Manufacturing", Journal of Development Economics, 66: 51-86.

[5] Bahk, B. and M. Gort (1993) - "Decomposing Learning by Doing in New Plants", Journal of Political Economy, 101: 561-583.

[6] Benkard L. (2000) - "Learning and Forgetting: The Dynamics of Aircraft Production", American Economic Review, 90: 4034-1054.

[7] Buera, F., J. Kaboski and Y. Shin (2011) - "Finance and Development: A Tale of Two Sectors", American Economic Review, 101: 1964-2002.

[8] Castro, R., G. Clementi and G. MacDonald (2009) - "Legal Institutions, Sectoral Heterogeneity and Economic Development", Review of Economic Studies, 76: 529-561. 
[9] Clementi, G. and H. Hopenhayn (2006) - "A Theory of Financing Constraints and Firm Dynamics", Quarterly Journal of Economics 121: 229-265.

[10] De Loecker, J. (2007) - "Do Exports Generate Higher Productivity", Journal of International Economics, 69-98.

[11] Djankov, S., O. Hart, C. McLiesh and A. Shleifer (2008) - "Debt Enforcement around the World", Journal of Political Economy 116, 6: 1105-1149.

[12] Erosa, A., and A. Hidalgo-Cabrillana (2010) - "On Capital Market Imperfections as a Source of Low TFP and Economic Rents", International Economic Review, 49: 437-473.

[13] Evans, D., (1987) - "The Relationship Between Firm Growth, Size, and Age: Estimates for 100 Manufacturing Industries", The Journal of Industrial Economics, 35: 566-581.

[14] Foster, L., J. Haltiwanger and C. Syverson (2008) - "Reallocation, Firm Turnover and Efficiency: Selection on Productivity or Profitability?", American Economic Review, 98: 394-425.

[15] Foster, L., J. Haltiwanger and C. Syverson (2013) - "The Slow Growth of New Plants: Learning about Demand", mimeo.

[16] Gomes, J. and L. Schmid (2010) - "Levered Returns", The Journal of Finance, 2: 467-494.

[17] Greenwood, J., J. Sanchez, and C. Wang (2013) - "Quantifying the Impact of Financial Development on Economic Development", American Economic Review, 100: 1875-1891.

[18] Hall, R. and Charles Jones (1999) - "Why Do Some Countries Produce So Much More Output per Worker than Others?", Quarterly Journal of Economics, 114, 83-116.

[19] Harvey, A. (1976) - "Estimating Regression Models with Multiplicative Heteroscedasticity", Econometrica, 44: 461-465.

[20] Hennessy, C. and T. Whited (2007) - "How Costly is External Financing? Evidence from a Structural Estimation", Journal of Finance, 62: 1705-1745.

[21] Hopenhayn H. (1992) - "Entry, Exit, and Firm Dynamics in Long Run Equilibrium", Econometrica, 60: $1127-1150$.

[22] Hsieh, C. and P. Klenow (2009) - "Misallocation and Manufacturing TFP in China and India", Quarterly Journal of Economics, 124: 1403-1448. 
[23] Huergo, E. and J. Jaimandreu (2004) - "How Does Probability of Innovation Change with Firm Age", Small Business Economics, 22: 193-207.

[24] Hyunh, K. and R. Petrunia (2013) - "Age Effects, Leverage and Firm Growth", Journal of Economic Dynamics and Control, forthcoming.

[25] Jensen, J. and R. McGuickin and K. Stiroh (2001) - "The Impact of Vintage and Survival on Productivity: Evidence from Cohorts of U.S. Manufacturing Plants", Review of Economics and Statistics, 83: 323-332.

[26] Jeong, H. and R. Townsend (2007) - "Sources of TFP Growth: Occupational Choice and Financial Deepening", Economic Theory, 32: 197-221.

[27] Jovanovic B. and Y. Nyarko (1996) - "Learning by Doing and the Choice of Technology", Econometrica, 64: 1299-1310.

[28] King, R. and R. Levine (1993) - "Finance, Entrepreneurship and Growth: Schumpeter Might Be Right", Quarterly Journal of Economics, 108: 717-737.

[29] Levine, O. and M. Warusawitharana (2013) - "Finance and Productivity Growth: Firm-Level Evidence", Working Paper.

[30] Levinsohn, J., and A. Petrin (2003) - "Estimating Production Functions Using Inputs to Control for Unobservables", Review of Economic Studies, 70: 317-341.

[31] Levinsohn, J. and M. Melitz (2006) - "Productivity in Differentiated Products Market Equilibrium", mimeo

[32] Levitt, S., J. List and C. Syverson (2013) - "Toward an Understanding of Learning by Doing: Evidence from and Automobile Plant", Journal of Political Economy, forthcoming

[33] OECD (2006) - "Structural and Demographic Business Statistics", Entrepreneurship Indicators Program

[34] Olley, S. and A. Pakes (1996) - "The Dynamics of Productivity in the Telecommunications Equipment Industry", Econometrica, 64: 1263-1297.

[35] Midrigan, V. and D. Xu (2013) - "Finance and Misallocation: Evidence from Plant-Level Data", American Economic Review, forthcoming 
[36] Syverson, C. (2004) - "Market Structure and Productivity: A Concrete Example", Journal of Political Economy, 112: 1181-1222.

[37] Thornton, R. and P. Thompson (2001) - "Learning from Experience and Learning from Others: An Exploration of Learning and Spillovers in Wartime Shipbuilding", American Economic Review, 1350-1368.

[38] Warusawitharana M. (2012) - "Research and Development, Profits and Firm Value: A Structural Estimation", mimeo.

[39] Wooldridge, J. (2002) - "Econometric Analysis of Cross Section and Panel Data", MIT Press. 


\section{Figures and Tables}

Figure 1: Indicators of Financial Development

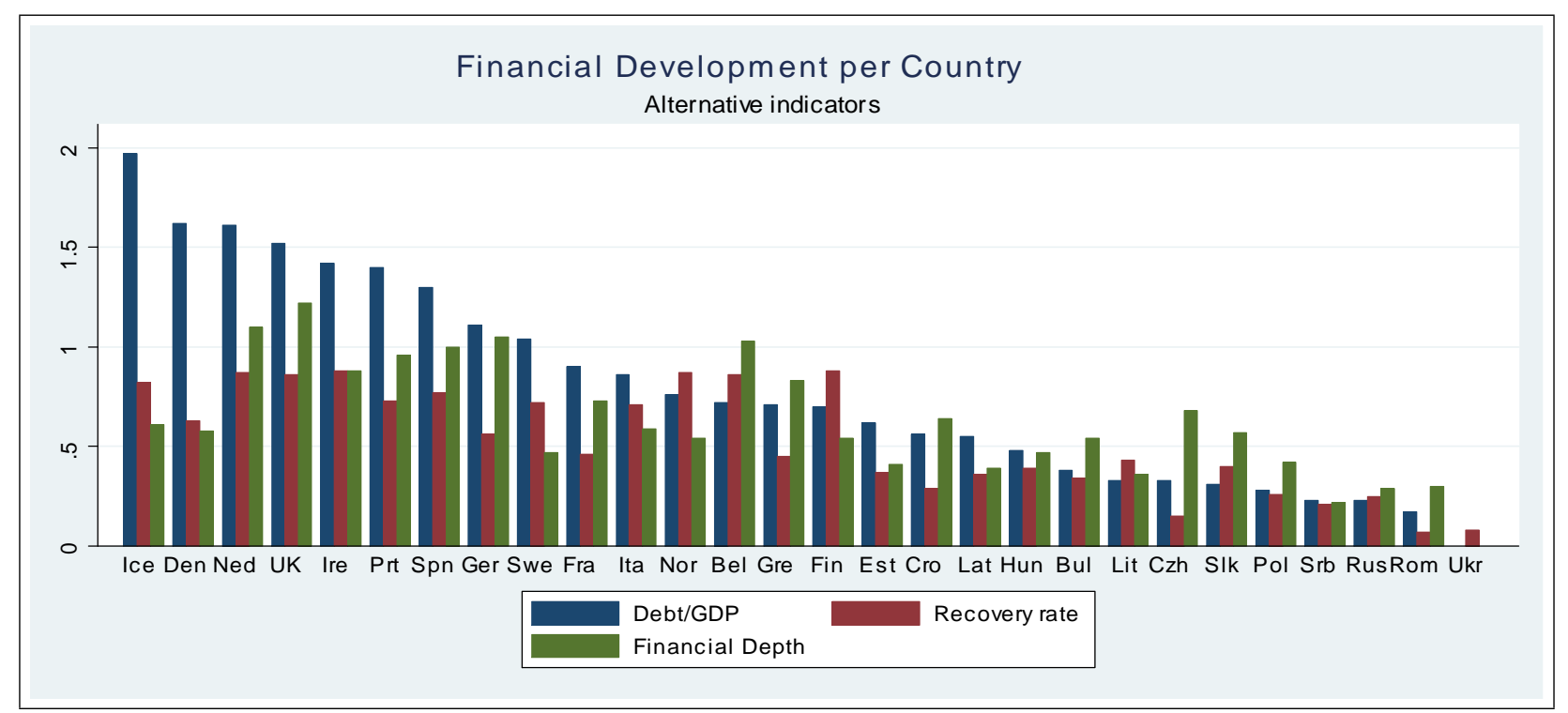

Note: Debt/GDP is the total private debt to GDP. Financial Depth is measured as the ratio of liquid liabilities of the financial system to GDP. Recovery rate is the expected amount recouped by creditors per dollar lent to a defaulting debtor. All indicators are country averages for the 2003-2006 period. 
Figure 2: Average TFPR across age-cohorts
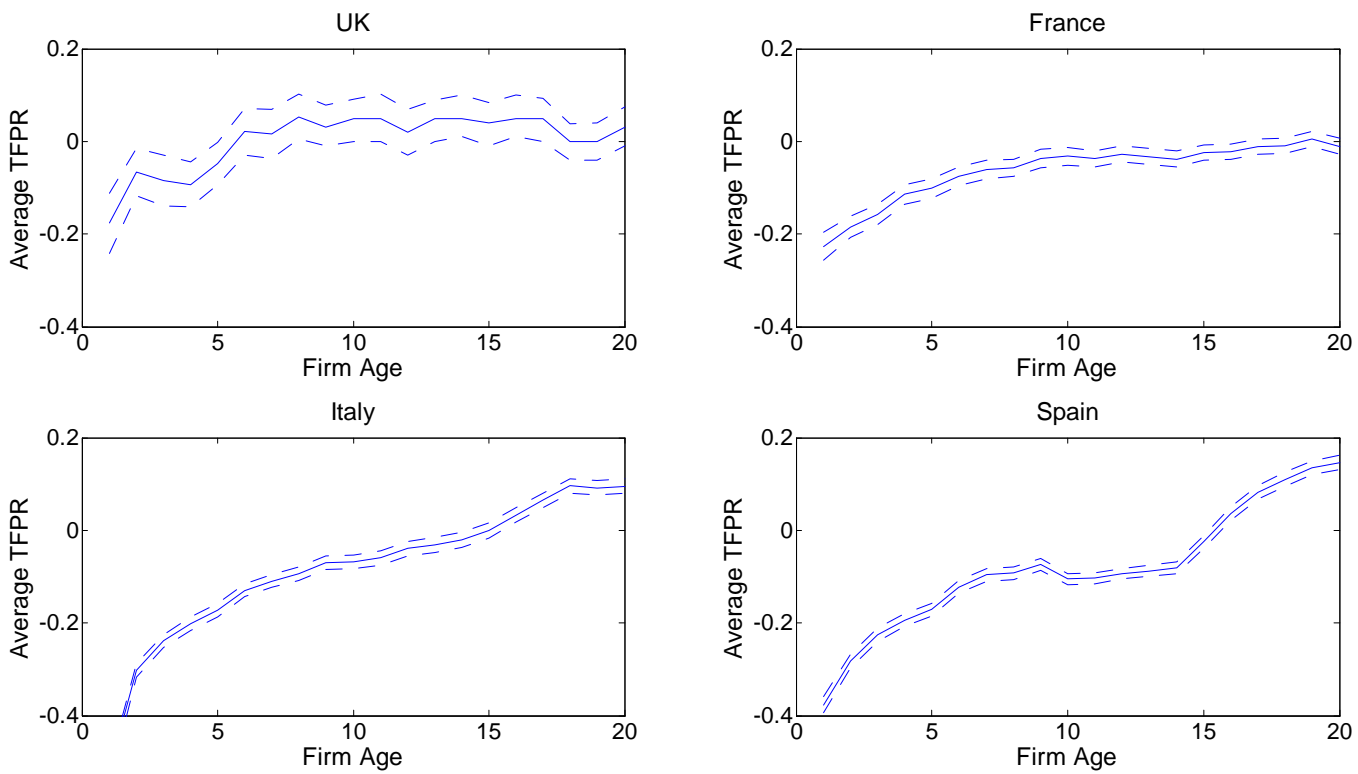

Note: The figure reports the average demeaned TFPR for each age-cohort for the four countries in the sample with the largest number of firms. The dashed lines delimit the 95 percent confidence interval.

Table 1: Regression - Firm Age and TFPR

\begin{tabular}{|c|c|c|c|c|c|c|}
\hline & \multicolumn{3}{|c|}{ UK } & \multicolumn{3}{|c|}{ France } \\
\hline & (1) & (2) & (3) & (1) & (2) & (3) \\
\hline & Benchmark & Firm FE & Heckit & Benchmark & Firm FE & Heckit \\
\hline \multirow[b]{2}{*}{$\ln$ (age) } & 0.01 & 0.05 & 0.518 & 0.10 & 0.06 & 0.25 \\
\hline & $(0.004)^{* * *}$ & $(0.018)^{* * *}$ & $(0.047)^{* * *}$ & $(0.017)^{* * *}$ & $(0.017)^{* * *}$ & $(0.026)^{*}$ \\
\hline \multirow[t]{4}{*}{ Obs. } & 31,127 & 31,127 & 12,325 & 113,175 & 113,175 & 42,097 \\
\hline & & Italy & & & Spain & \\
\hline & (1) & $(2)$ & (3) & (1) & $(2)$ & (3) \\
\hline & Benchmark & Firm FE & Heckit & Benchmark & Firm FE & Heckit \\
\hline \multirow{2}{*}{$\ln ($ age $)$} & 0.19 & 0.16 & 0.83 & 0.25 & 0.17 & 0.17 \\
\hline & $(0.001)^{* * *}$ & $(0.006)^{* * *}$ & $(0.009)^{* * *}$ & $(0.002)^{* * *}$ & $(0.005)^{* * *}$ & $(0.008)^{* * *}$ \\
\hline Obs. & 256,995 & 256,995 & 124,296 & 267,819 & 267,819 & 108,748 \\
\hline
\end{tabular}

Note: This table presents the results of regressing the TFPR of a firm on its log-age for the 2006-2009 period. Firm TFPR was estimated using the method proposed by Levinsohn and Petrin (2003). The benchmark regression does not include firm fixed-effects whereas the other two do. All regressions have industry-year fixed-effects. Heckit regressions control for selection using the Heckman two-step procedure. Due to lower quality in the selection indicator, the Heckit regression uses a sample from 2007-2008. The probit in the first step regresses the selection indicator on the firm productivity, size and age. 
Figure 3: Standard deviation of sales growth and firm age
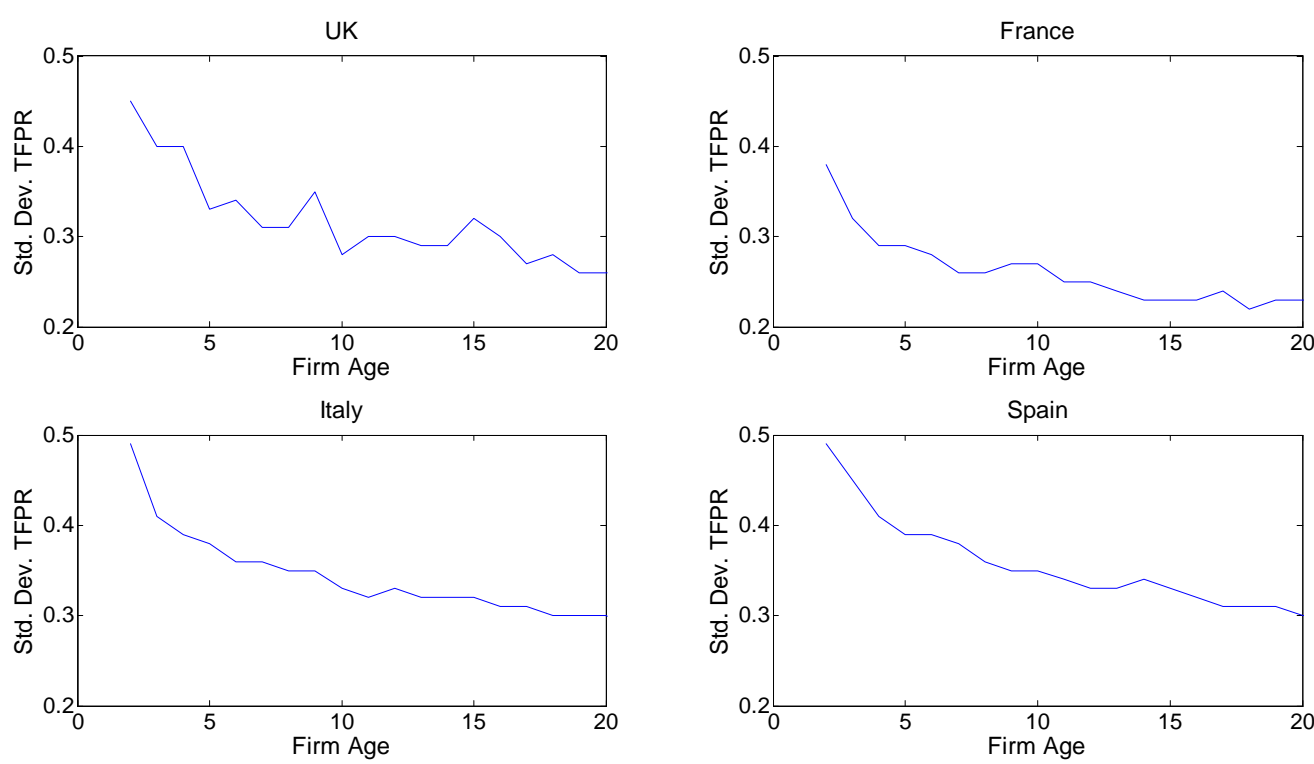

Note: The figure reports the average standard deviation of TFPR growth as for each age-cohort for the four countries in the sample with the largest number of firms.

Table 2: Regression - Firm Age and Std. Dev. of Sales Growth

\begin{tabular}{|c|c|c|c|c|c|c|c|c|}
\hline & \multicolumn{2}{|c|}{ UK } & \multicolumn{2}{|c|}{ France } & \multicolumn{2}{|c|}{ Italy } & \multicolumn{2}{|c|}{ Spain } \\
\hline & (1) & (2) & (1) & (2) & (1) & (2) & (1) & (2) \\
\hline Age-Group - $\tau$ & All Firms & Heckit. & All Firms & Heckit. & All Firms & Heckit. & All Firms & Heckit. \\
\hline $\operatorname{age}_{i, t} \in[0,3]$ & 0.121 & 0.110 & 0.111 & 0.117 & 0.132 & 0.148 & 0.156 & 0.153 \\
\hline$a g e_{i, t} \in[4,7]$ & 0.105 & 0.096 & 0.095 & 0.099 & 0.119 & 0.0116 & 0.138 & 0.133 \\
\hline $\operatorname{age}_{i, t} \in[8,12]$ & 0.090 & 0.087 & 0.087 & 0.089 & 0.108 & 0.098 & 0.120 & 0.115 \\
\hline$a g e_{i, t} \geq 13_{j}$ & 0.076 & 0.075 & 0.071 & 0.073 & 0.089 & 0.089 & 0.100 & 0.101 \\
\hline Observations & 27,727 & 13,505 & 88,991 & 45,827 & 144,347 & 82,742 & 209,344 & 110,505 \\
\hline
\end{tabular}

Note: This table presents the results of the persistence and variance of the productivity process. These countries were chosen as they have the largest number of firms. 
Table 3: Calibrated Parameters

\begin{tabular}{lccc}
\hline \hline \multicolumn{1}{c}{ Assigned Parameters } & Parameter & Value \\
\hline Intertemporal elasticity of substitution & \multicolumn{2}{c}{} \\
Riskless interest rate & $R_{f}$ & \multicolumn{2}{c}{0.04} \\
Depreciation rate & $\delta$ & \multicolumn{2}{c}{0.06} \\
Shr. of output to entrepreneur & $\alpha+\gamma$ & \multicolumn{2}{c}{0.85} \\
Capital share & $\alpha$ & \multicolumn{2}{c}{0.33} \\
Autoregressive parameter & $\rho$ & \multicolumn{2}{c}{0.35} \\
Discount Rate - Entrepreneurs & $\beta$ & \multicolumn{2}{c}{0.92} \\
\hline \multicolumn{1}{c}{ Calibrated parameters } & \multicolumn{4}{c}{ No-Learning } & Learning \\
Permanent productivity & $\mu$ & 6.8 & 6.95 \\
Probability of permanent shock & $\kappa$ & 0.08 & 0.08 \\
Residual share kept by defaulter & $\varkappa$ & 0.85 & 0.85 \\
Stochastic shock standard deviation & $\sigma_{\varepsilon}$ & 0.175 & 0.13 \\
Adjustment & $s$ & 0 & -0.62 \\
Probability of adjustment & $p$ & 0 & 0.27 \\
\hline
\end{tabular}

Note: This table reports the parameter values used in the simulations. The Assigned Parameters were obtained, for comparison purposes, from a series of related quantitative studies. The Calibrated Parameters minimized the distance between a series of relevant moments of the simulations and of the data. Learning (No-Learning), reports the estimated parameters in a scenario where the productivity process is (is not) related with firm age.

Table 4: Targeted Moments

\begin{tabular}{lccccc}
\hline \hline & & \multicolumn{2}{c}{ No-Learning } & \multicolumn{2}{c}{ Learning } \\
& Data - UK & Model & Model & Model & Model \\
Target Moments & $\xi=0.85$ & $\xi=0.85$ & $\xi=0.25$ & $\xi=0.85$ & $\xi=0.25$ \\
\cline { 2 - 6 } Top 10-pct. empl. share & 0.69 & 0.69 & 0.71 & 0.69 & 0.86 \\
St. dev. sales & 0.61 & 0.61 & 0.56 & 0.68 & 0.63 \\
St. dev. sales $<8$ yrs & 0.75 & 0.64 & 0.54 & 0.75 & 0.93 \\
St. dev. sales $\geq 8$ yrs & 0.53 & 0.57 & 0.57 & 0.55 & 0.58 \\
Default Rate $<250$ empl & 0.06 & 0.06 & 0.06 & 0.06 & 0.02 \\
TFPR old/TFPR new & 1.12 & 1.03 & 1.16 & 1.11 & 0.67 \\
Exit rate $\geq 10$ yrs & 0.07 & 0.07 & 0.08 & 0.08 & 0.01 \\
\hline
\end{tabular}

Note: This table reports the target moments used in estimating the parameters of the model. Values in italic denote moments not used directly in the estimation. Learning (No-Learning), reports the estimated parameters in a scenario where the productivity process is (is not) related with firm age. 
Figure 4: Policy functions: Learning vs. No-Learning
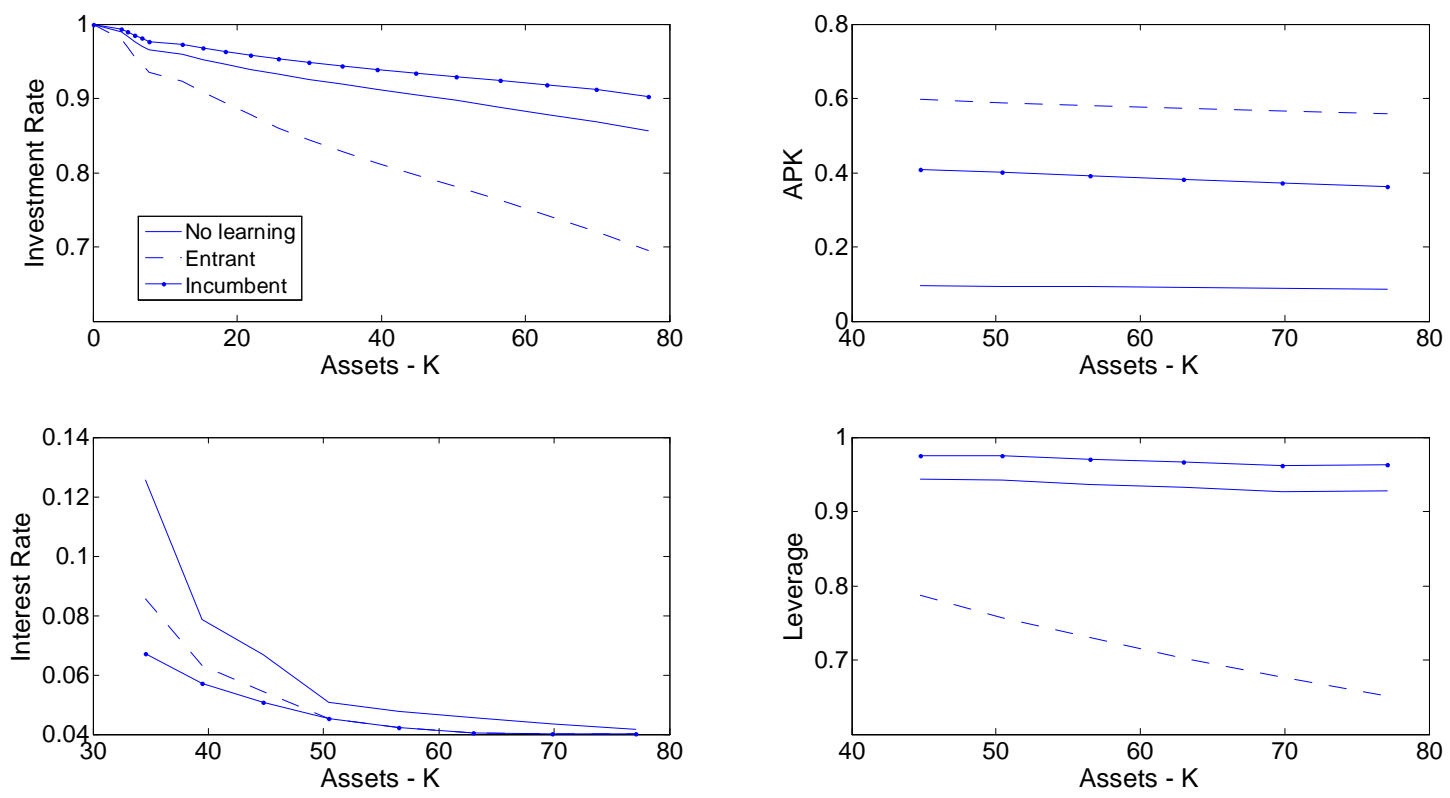

Note: This figure depicts the decisions of entrepreneurs with median talent and no debt for various levels of assets. It contrasts the decisions in a scenario where there is no relation between the productivity process and firm age (No-Learning) with one where there is. Furthermore, in the Learning scenario I graph the dynamics of both an entrant firm - age $<6$ years - and of an older firm. MPK is the marginal productivity of capital whereas Leverage is defined as the ratio of total liabilities to total assets. 
Figure 5: Firm dynamics in scenarios with and without Learning
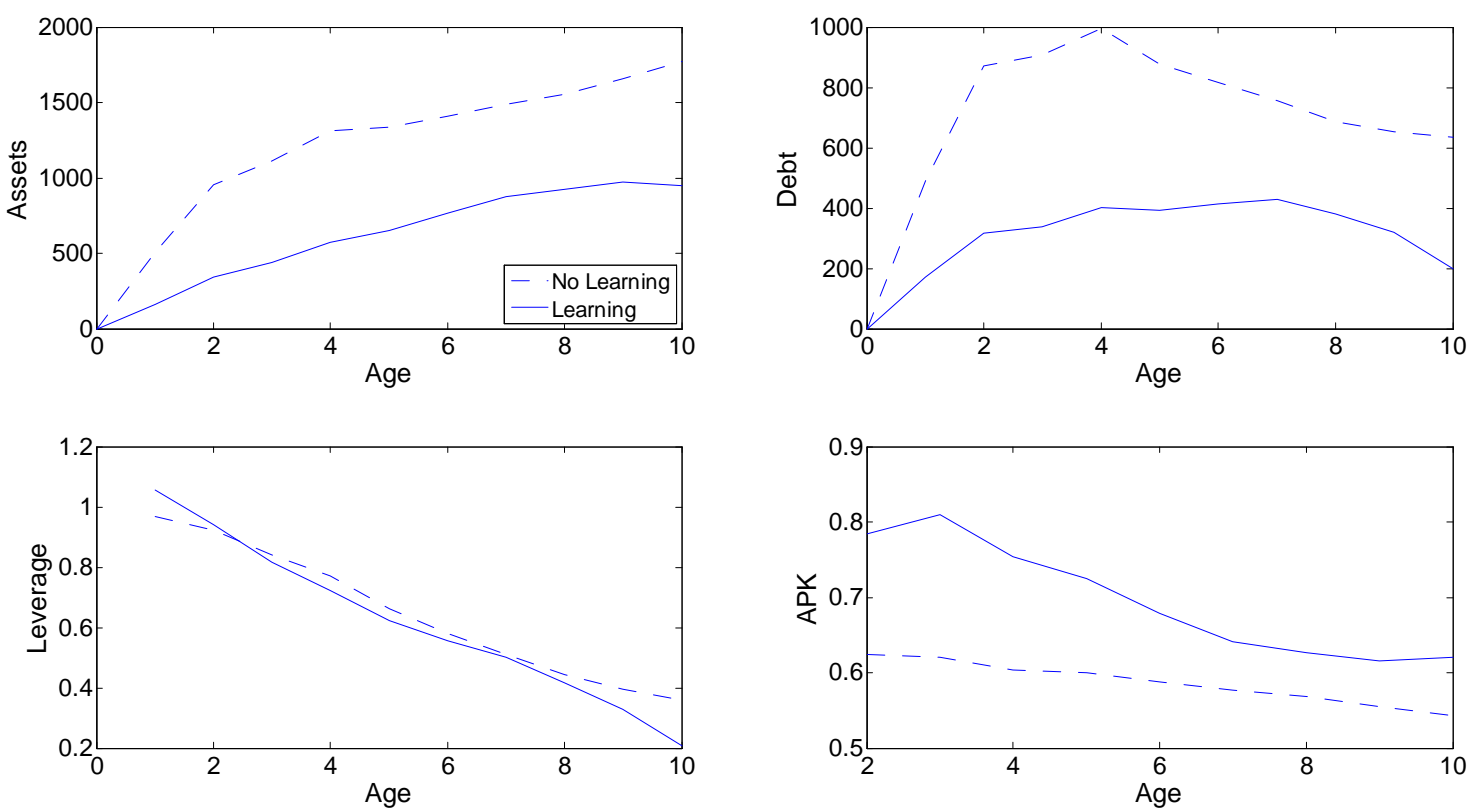

Note: This figure illustrates the evolution of a firm as it grows older in a scenario with and without Learning. MPK is the marginal productivity of capital whereas Leverage is defined as the ratio of total liabilities to total assets. In both scenarios, firms start without assets and debt, and with the same productivity throughout their life. 
Table 5: Additional moments

\begin{tabular}{lccccc}
\hline \hline & & \multicolumn{2}{c}{ No-Learning } & \multicolumn{2}{c}{ Learning } \\
\cline { 2 - 5 } \multicolumn{1}{c}{ Additional Moments } & Data - UK & Model & Model & Model & Model \\
Share of sales - 1-5 years & $\xi=0.85$ & $\xi=0.85$ & $\xi=0.25$ & $\xi=0.85$ & $\xi=0.25$ \\
\cline { 2 - 6 } Share of sales - 6-10 years & 0.11 & 0.20 & 0.12 & 0.12 & 0.03 \\
Fraction of firms - 1-5 years & 0.16 & 0.19 & 0.11 & 0.17 & 0.08 \\
Fraction of firms - 6-10 years & 0.31 & 0.42 & 0.50 & 0.42 & 0.04 \\
Average firm employment & 0.20 & 0.15 & 0.12 & 0.15 & 0.05 \\
Average firm employment $<5$ years & 22 & 18.9 & 17.5 & 19.5 & 73.2 \\
Average firm employment $\geq 5$ years & 11.0 & 8.0 & 4.0 & 4.8 & 33.3 \\
Leverage (Debt/Assets) & 35.5 & 30.4 & 36.5 & 32.2 & 90.2 \\
Leverage - 1-5 years & 0.73 & 0.57 & 0.16 & 0.63 & 0.26 \\
Leverage - 6 $\leq$ years & 0.81 & 0.83 & 0.23 & 0.82 & 0.59 \\
Average interest rate $<5$ years & - & 0.48 & 0.15 & 0.59 & 0.26 \\
Average interest rate $\geq 5$ years & - & 0.05 & 0.13 & 0.05 & 0.11 \\
Exit rate & 0.11 & 0.05 & 0.07 & 0.04 & 0.05 \\
Top 5-pct earnings share & 0.31 & 0.14 & 0.23 & 0.15 & 0.01 \\
Debt/GDP & 2.40 & 1.25 & 0.40 & 0.33 & 0.41 \\
\hline
\end{tabular}

Note: This table reports a series of relevant moments, empirical and simulated, that were not directly targeted by the calibration. Learning (No-Learning) reports the moments in an economy where firm productivity is (is not) related with firm age. distribution of firms, 
Figure 6: Firm dynamics under different recovery rates
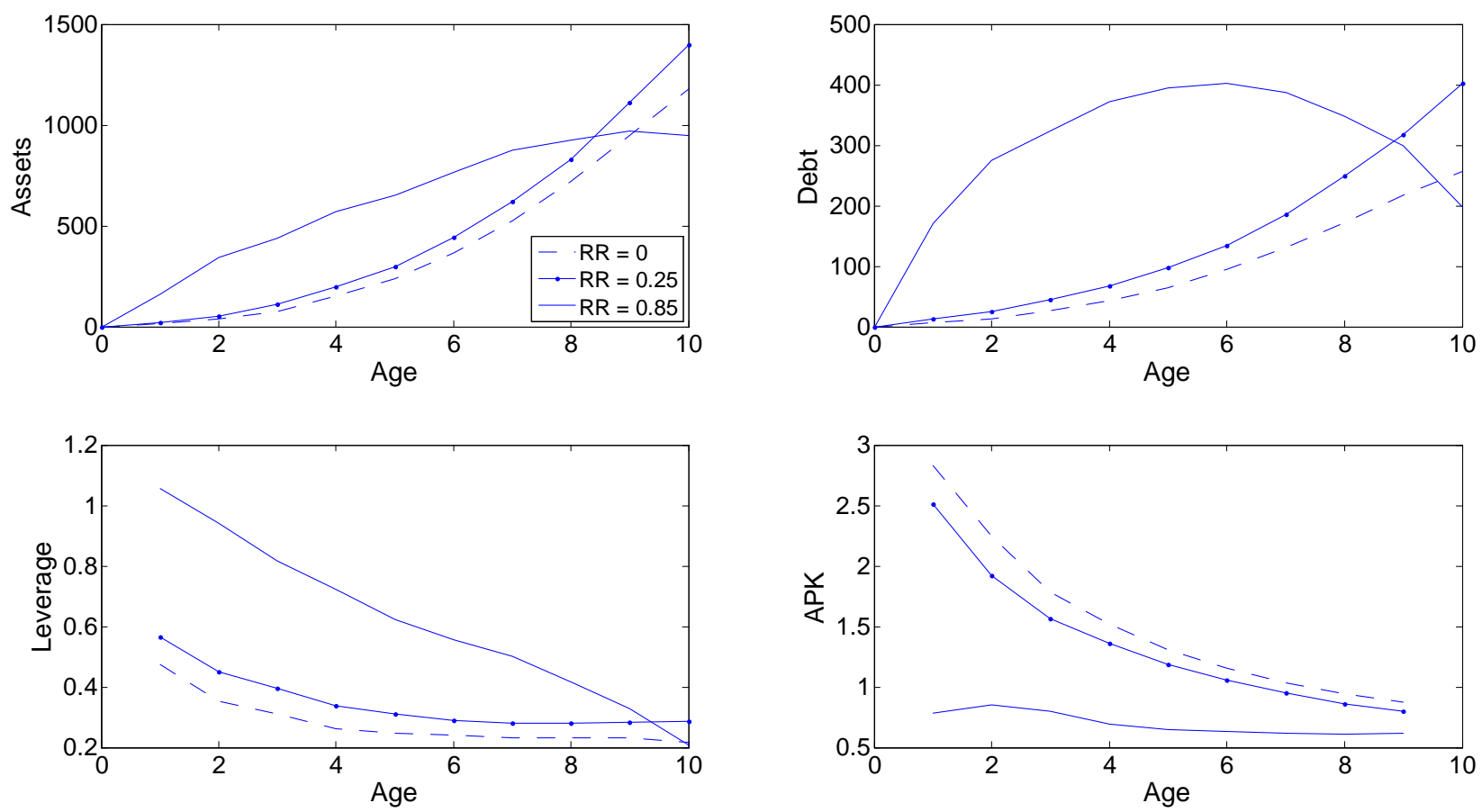

Note: This figure illustrates the evolution of a firm as it grows older in a scenario with Learning under different levels of recovery rate. In all simulations productivity is set to its median value throughout the life of the firm. MPK is the marginal productivity of capital whereas Leverage is defined as the ratio of total liabilities to total assets. 
Table 6: Financial Development and Average Production of Capital - Data and Model

\begin{tabular}{lcccc}
\hline \hline & \multicolumn{4}{c}{ Model } \\
\multicolumn{1}{c}{ Panel $A$} & $\xi=0.65$ & $\xi=0.35$ & $\xi=0.65$ & $\xi=0.35$ \\
All-firms & 0.52 & 0.53 & 0.56 & 0.56 \\
Young & 0.75 & 1.44 & 0.77 & 0.69 \\
Mature & 0.53 & 0.49 & 0.54 & 0.55 \\
Productive & 0.58 & 0.54 & 0.60 & 0.61 \\
Young-productive & 1.07 & 1.86 & 0.99 & 1.63 \\
Mature-productive & 0.56 & 0.55 & 0.56 & 0.58 \\
St. Dev. & 0.65 & 0.72 & 0.64 & 0.75 \\
St. Dev. Young & 0.75 & 0.78 & 0.70 & 0.84 \\
\hline \multicolumn{5}{c}{ Data } \\
\hline \multicolumn{1}{c}{ Panel B } & High recovery rate Low recovery rate \\
All-firms & 1.54 & \multicolumn{4}{c}{1.82} \\
Young & 1.69 & 2.13 \\
Mature & 1.49 & 1.67 \\
Productive & 1.98 & 2.74 \\
Young-productive & 2.34 & \multicolumn{4}{c}{3.11} \\
Mature-productive & 1.91 & \multicolumn{4}{c}{1.50} \\
St. Dev. & 1.09 & \multicolumn{4}{c}{1.36} \\
St. Dev. Young & 1.39 &
\end{tabular}

Note: This table reports the empirical and simulated average productivity of capital (APK) - ratio of sales to assets - for a series of cross-sectional groups defined by the age of the firm and its relative productivity. In Panel B, I report the empirical median APK of firms. Countries are split into two groups: A country has high (low) recovery rate if it is above (below) 0.4 . For high (low) recovery rate countries their average recovery rate is 0.69 (0.49). I classify firms to be young (mature) if they are younger (older) than 5 years old. Furthermore, a firm is considered Productive if its TFPR is in the top-10 percentile. In Panel B, I use sales and not value added due to the lack of data either on materials or on value added for certain countries. To correct for outliers, in all countries, I dropped the top and bottom 1 percent of APK observations. 
Table 7: Regressions - Data and Model Simulations

\begin{tabular}{|c|c|c|c|c|c|c|}
\hline \multirow{4}{*}{$\ln a g e$} & \multicolumn{6}{|c|}{ Data } \\
\hline & \multicolumn{2}{|c|}{ TFPR } & \multicolumn{2}{|c|}{ Std. TFPR } & \multicolumn{2}{|c|}{ Leverage } \\
\hline & 0.057 & 0.052 & -0.061 & -0.246 & -0.049 & -0.052 \\
\hline & $(0.001)^{* * * *}$ & $(0.004)^{* * *}$ & $(0.114)^{* * *}$ & $(0.113)^{* *}$ & $(0.001)^{* * *}$ & $(0.001)^{* * * *}$ \\
\hline$F D \times \ln a g e$ & & 0.001 & & 0.047 & & -0.003 \\
\hline FD $\times$ X III age & & $(0.000)^{* *}$ & & $(0.028)^{*}$ & & $(0.003)^{* * * *}$ \\
\hline $\operatorname{Adj} \cdot R^{2}$ & 0.52 & 0.49 & 0.03 & 0.03 & 0.06 & 0.06 \\
\hline \multirow[t]{4}{*}{ Obs. } & $1,025,555$ & 552,203 & 1,454 & 1,454 & $3,012,464$ & $1,417,287$ \\
\hline & \multicolumn{6}{|c|}{ Model } \\
\hline & \multicolumn{2}{|c|}{ TFPR } & \multicolumn{2}{|c|}{ Std. TFPR } & \multicolumn{2}{|c|}{ Leverage } \\
\hline & No-Learn & Learn & No-Learn & Learn & No-Learn & Learn \\
\hline & 0.09 & -0.04 & 0.00 & -0.44 & -0.29 & -0.28 \\
\hline $\ln a g e$ & $(0.001)^{* * *}$ & $(0.001)^{* * *}$ & $(0.00)$ & $(0.02)^{* * *}$ & $(0.001)^{* * *}$ & $(0.001)^{* * *}$ \\
\hline$E D \times \ln g a$ & 0.03 & 0.10 & 0.00 & 0.01 & 0.24 & 0.22 \\
\hline$F D \times \ln a g e$ & $(0.001)^{* * *}$ & $(0.001)^{* * *}$ & $(0.00)$ & $(0.00)^{* * *}$ & $(0.001)^{* * *}$ & $(0.001)^{* * *}$ \\
\hline $\operatorname{Adj} . R^{2}$ & 0.11 & 0.07 & 543 & 674 & 0.48 & 0.48 \\
\hline
\end{tabular}

Note: This table represents the coefficients of a series of regressions using data and using the simulated observations. The three dependent variables are TFPR (revenue-TFP), Growth (log-asset growth rate) and Leverage (ratio of total liabilities to total assets). FD denotes financial development and is measured by the recovery rate in case of default. All regressions have a fixed effect at the country-industry-year level. The standard errors reported in parentheses are robust to heteroskedasticity. 
Figure 7: Firm dynamics - TFPR
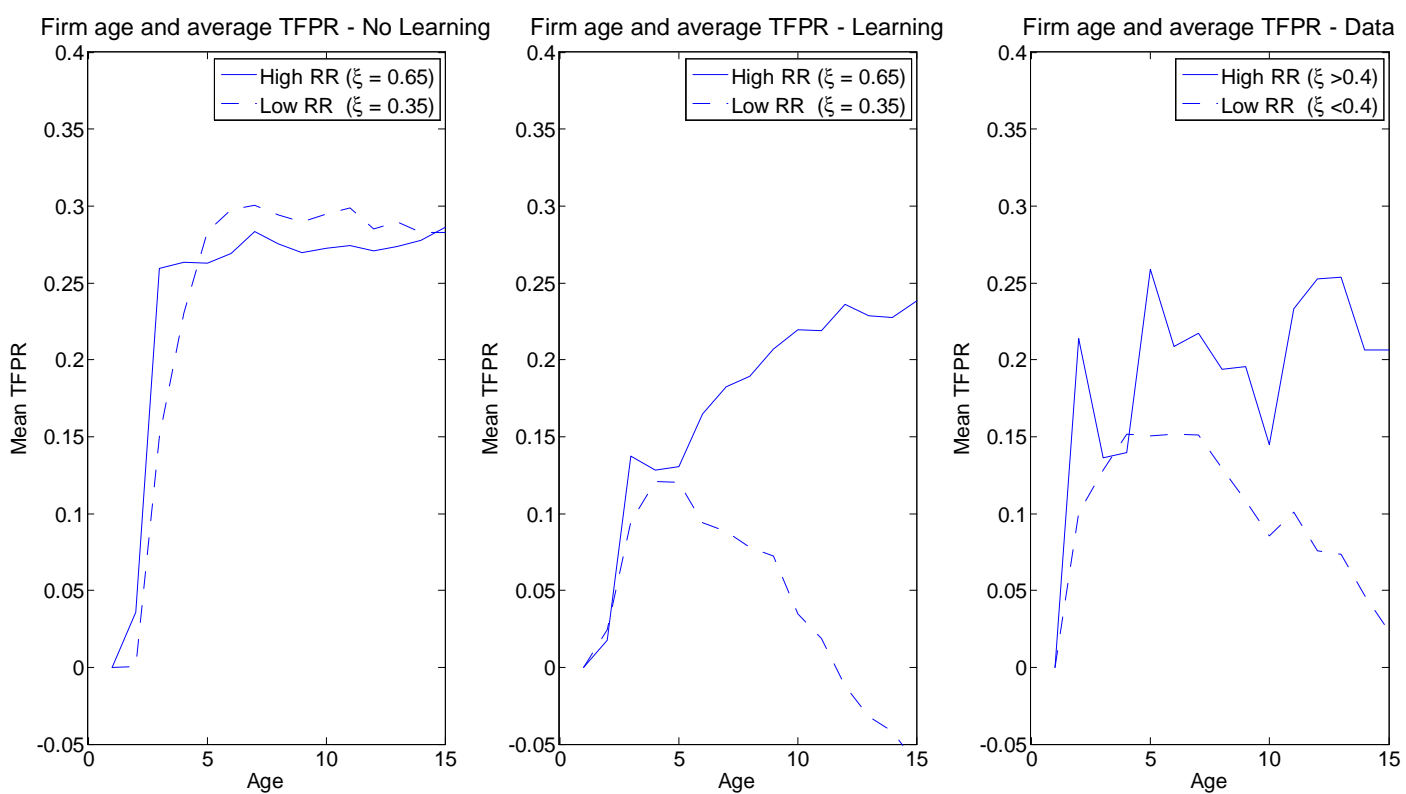

Note: This figure represents the average dynamics as simulated firms grow older in scenarios with high and low recovery rate. TFPR is the log revenue-productivity. 
Figure 8: Average TFPR across age-cohorts - Countries with low Recovery Rate
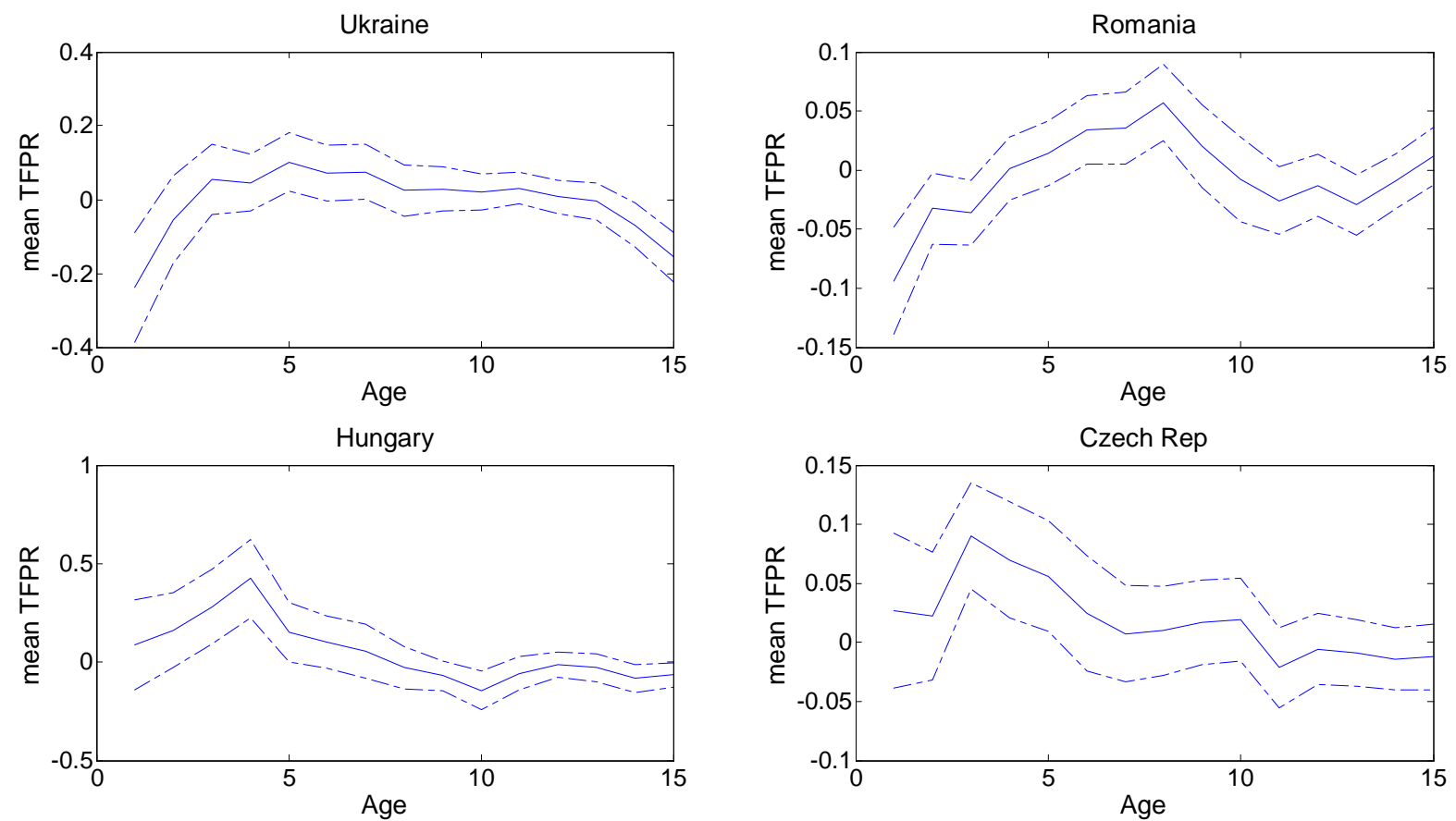

Note: The figure reports the average TFPR as a function of age for the four countries in the sample with the low Recovery Rate. The dashed lines delimit the 95 percent confidence interval. 
Figure 9: Firm dynamics - Std. Dev. TFPR
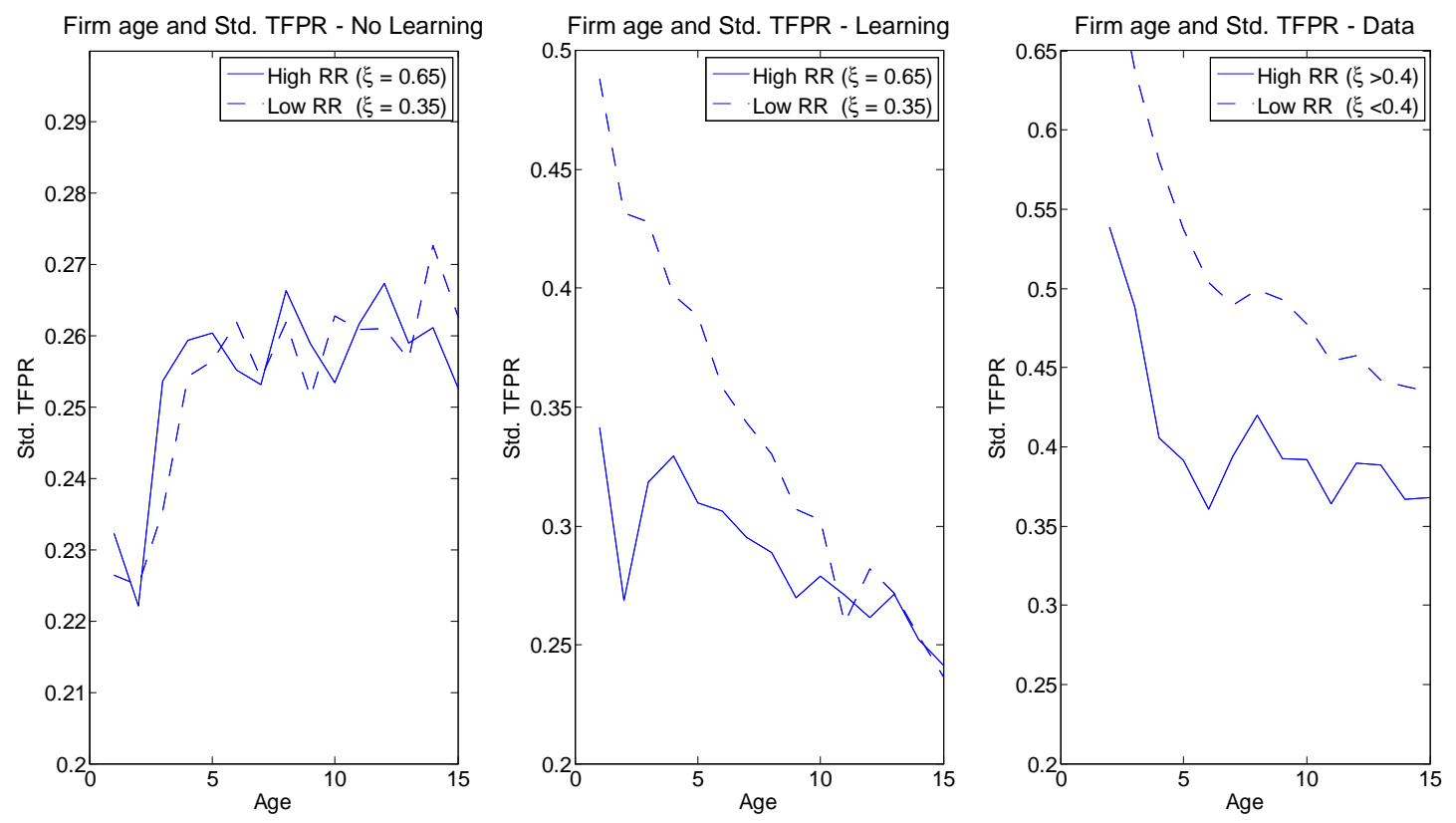

Note: This figure represents the average dynamics as simulated firms grow older in scenarios with high and low recovery rate. Std. TFPR is the standard deviation of the log revenue-productivity.growth for firms of a given age-cohort. 
Figure 10: Firm dynamics - Leverage
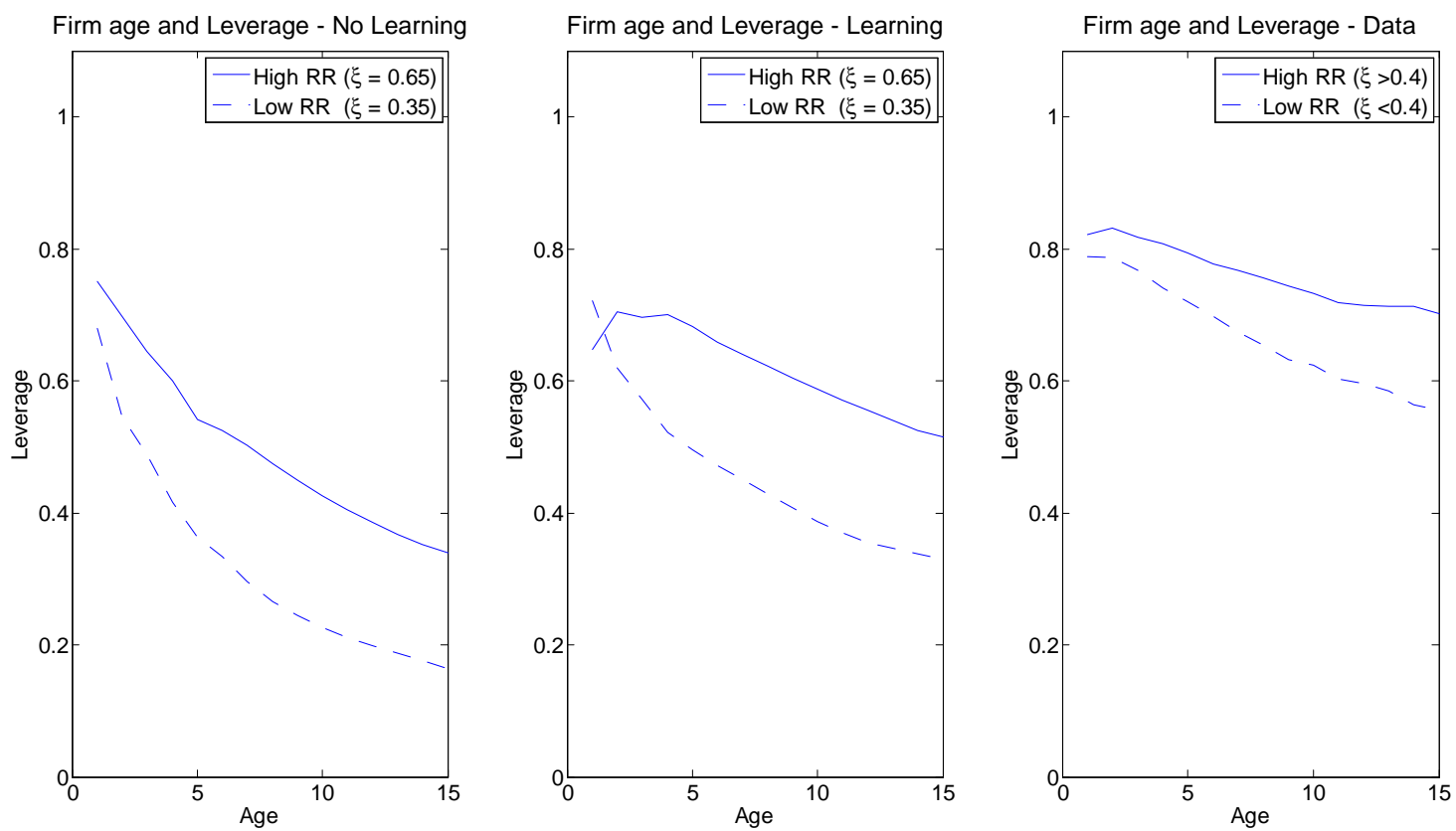

Note: This figure represents the average dynamics as simulated firms grow older in scenarios with high and low recovery rate. Leverage is the ratio of total debt to assets. 
Figure 11: Financial Development and Aggregate Outcomes
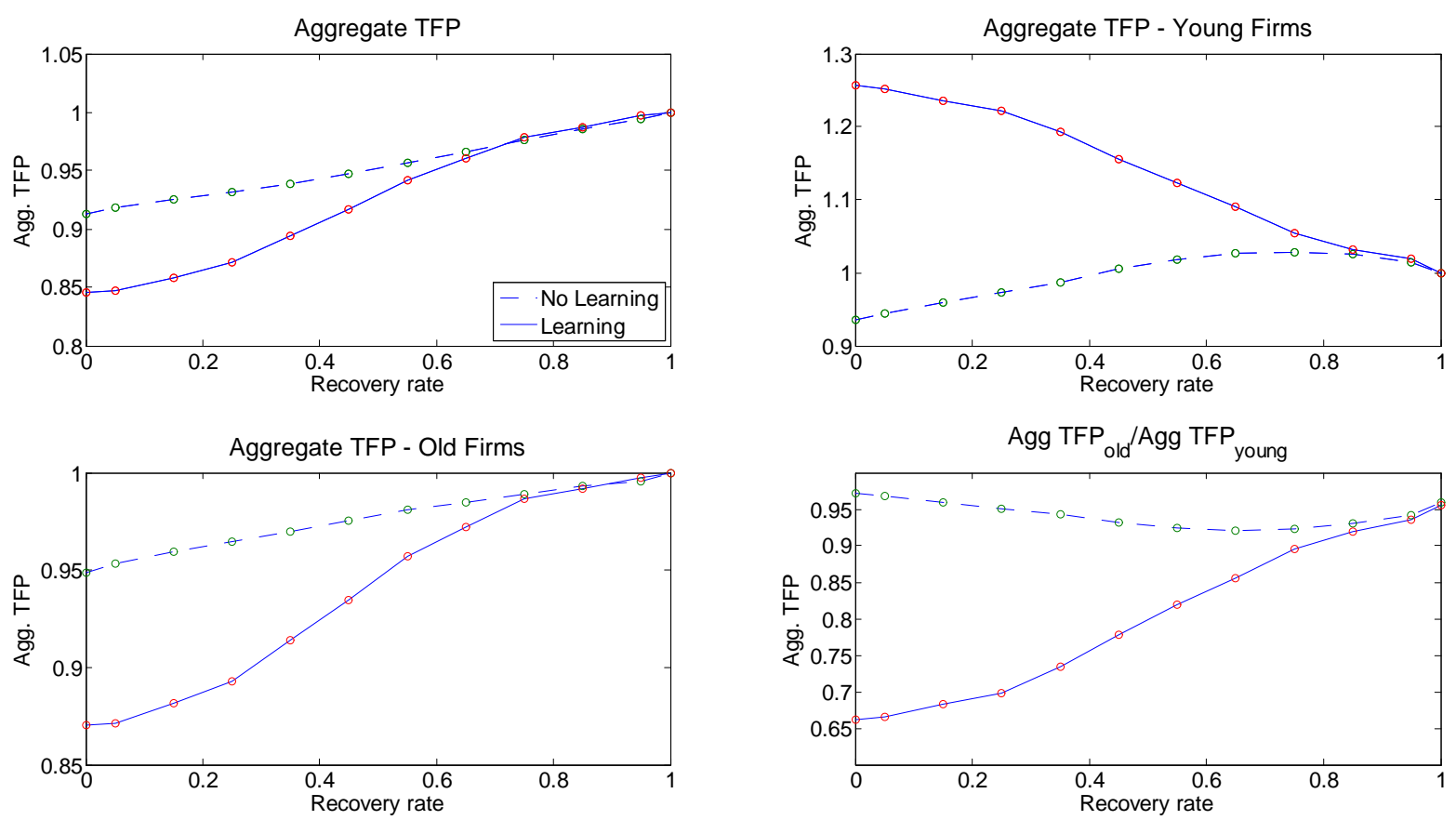

Note: This figure reports relation between the recovery rate and a series of country-level indicators. I graph both the empirical results as well as the results from the simulated model with and without learning. The lines indicate the best fit under OLS. The solid plot is the line of best fit for the data, whereas the dashed (crossed) line is the best fit for the No-Learning (Learning) model. 
Figure 12: Relative aggregate TFP - Old vs. New firms

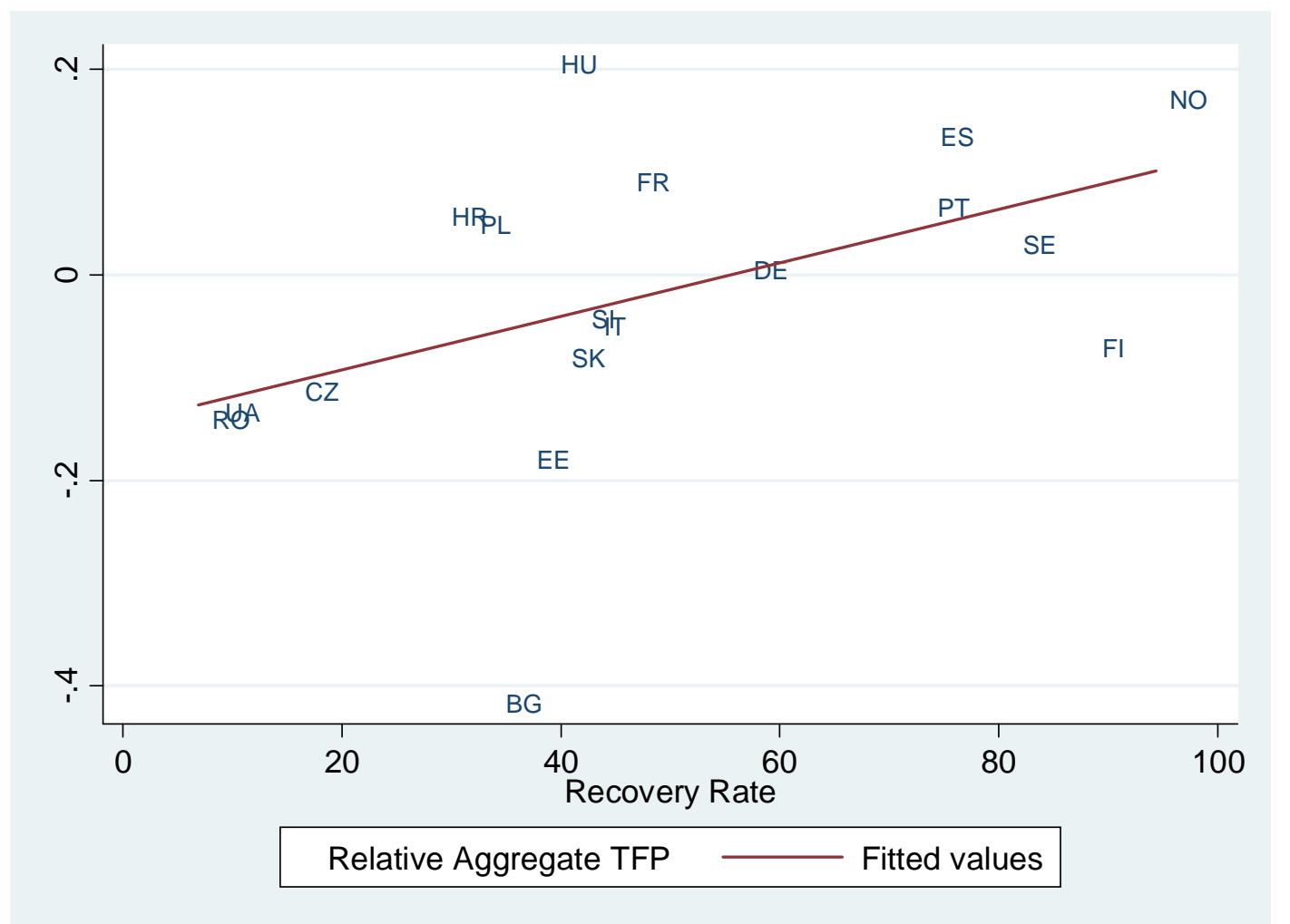

Note: This figure graphs the aggregate TFP of new firms with less than eight years-old relative to that of older firms $\left(\frac{T F P_{\text {old }}-T F P_{\text {old }}}{T F P_{\text {new }}}\right)$. The relation between recovery rate and the relative aggregate TFP is positive and significant both with and without Bulgaria. The correlation between recovery rate and the relative aggregate TFP is 0.46 with Bulgaria and 0.52 without it. 
Figure 13: Financial Development and Aggregate Outcomes
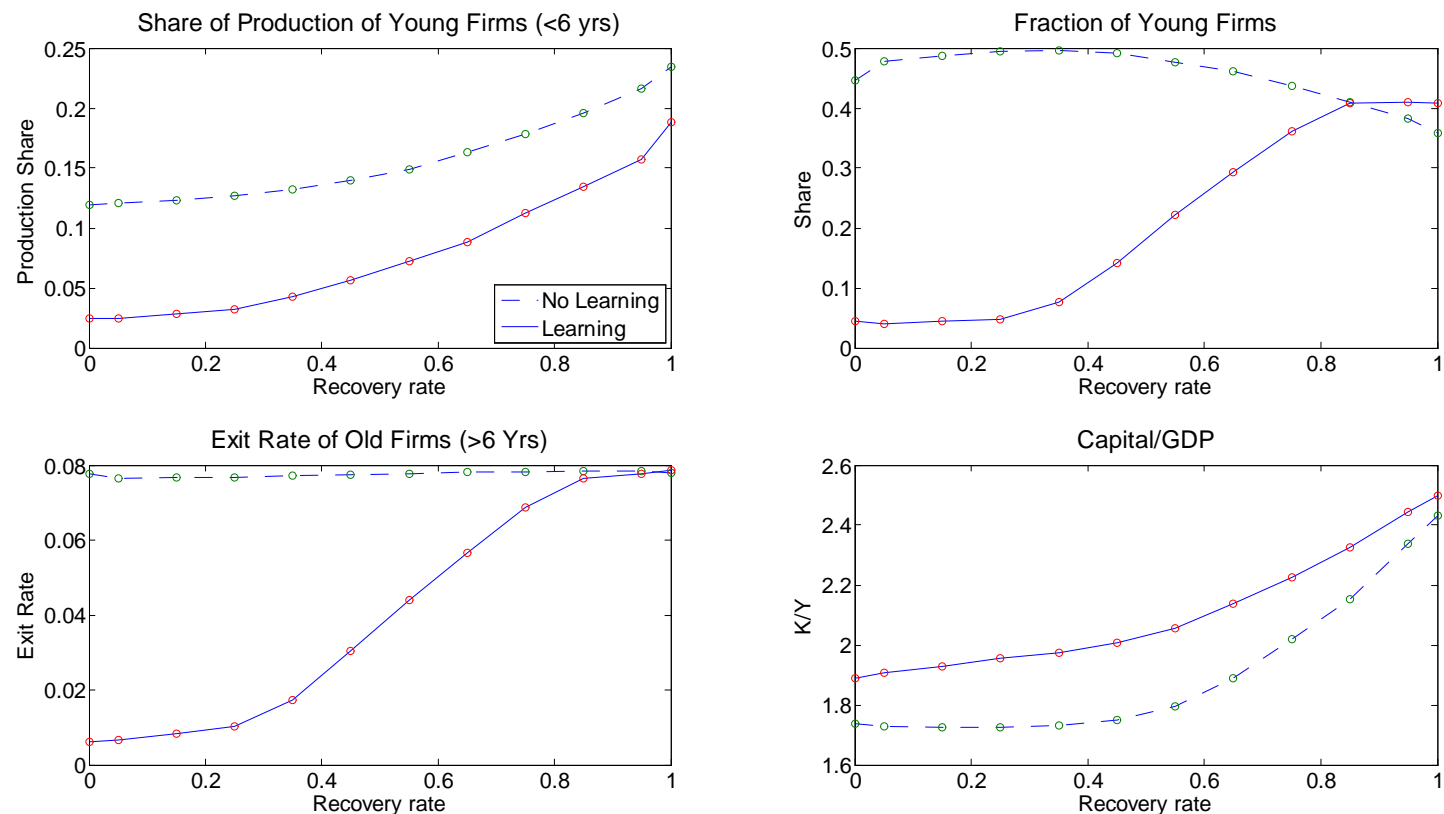

Note: This figure reports relation between the recovery rate and a series of indicators. I graph the results from the simulated model with and without learning. The lines indicate the best fit under OLS. The solid (dashed) line is the best fit for the No-Learning (Learning) model. 
Figure 14: Misallocation of Factors of Production
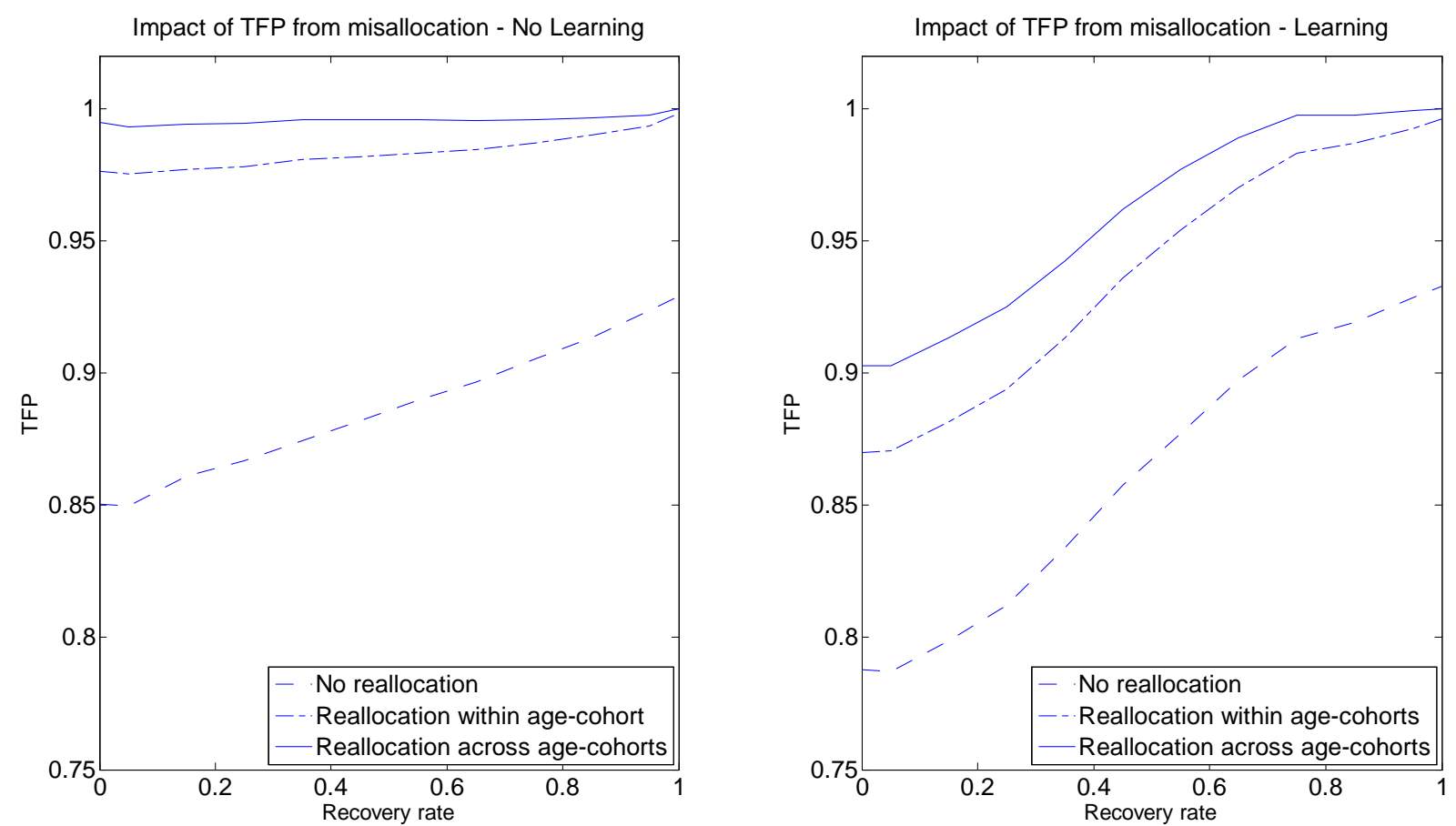

Note: This figure graphs the impact that misallocation of the factors of production has on aggregate TFP. All values are relative to the aggregate TFP with complete reallocation when the recovery rate is 1 .

\section{Appendix}

\subsection{Productivity Estimation}

\subsubsection{Levinsohn and Petrin}

The algorithm is as follows. Firm profits are a function of the firm's state variables and factor prices which are common across all firms. Assuming a Cobb-Douglas production function, the estimating equation for company $i$ in industry $j$ at time $t$ is

$$
y_{i t}=\beta_{0}+\beta_{l} l_{i, j, t}+\beta_{k} k_{i, j, t}+\beta_{m} m_{i, j, t}+\omega_{i, j, t}+\eta_{i, j, t}
$$

where $\{y, l, k, m\}$ are the $\log$ value of sales, number of employees, fixed assets and materials. Note that production depends, in addition to the inputs, on a firm specific productivity shock $\omega_{i t}$ and on 
an unpredictable measurement error unrelated to the input's choice $\eta_{i t}$. Although both $\omega$ and $\eta$ are unobserved, the former is a serially correlated state variable that impacts the firm's decisions on input demand, whereas the latter is not. To address the simultaneity-bias, I use intermediate inputs' demand as proxy variable for productivity. Under certain conditions, the demand of intermediate inputs is strictly monotonic in the productivity of the firms. ${ }^{52}$ Inverting $m_{i t}=f_{t}\left(\omega_{i t}, k_{i t}\right)$ provided that the monotonicity condition holds, the demand for intermediate inputs can be inverted in productivity $\omega_{i t}=f_{t}^{-1}\left(m_{i t}, k_{i t}\right)$ and therefore unobserved productivity can be approximated by the function $f^{-1}(\cdot)$, which depends only on observables. Substituting this expression in the production function,

$$
y_{i t}=\beta_{l} l_{i t}+\phi_{t}\left(m_{i t}, k_{i t}\right)+\eta_{i t}
$$

where $\phi_{t}(\cdot)=\beta_{k} k_{i t}+\beta_{m} m_{i t}+f_{t}^{-1}\left(m_{i t}, k_{i t}\right)$. In the first stage of the routine of LP, a consistent estimator for the labor coefficient and for the composite term $\widehat{\phi}_{i t}$ can be obtained by treating the function $f^{-1}(\cdot)$ nonparametrically. ${ }^{53}$ Note that $\beta_{k}$ and $\beta_{m}$ cannot be identified in this stage since they appear both linearly and in the non-parametric term. In the second stage the coefficients $\beta_{m}$ and $\beta_{k}$ are identified by GMM procedures using the moment condition

$$
E\left\{\xi_{i j t}\left(\beta_{k}, \beta_{m}\right)\left(\begin{array}{c}
k_{i t} \\
m_{i t-1}
\end{array}\right)=0\right\}
$$

Due to the small number of companies in some of the four-digit level companies, I estimate the coefficients at the two digit NACE classification.

\subsubsection{Solow residual}

With this method, TFPR is computed in the typical index form

$$
t f p_{i, j, t}=y_{i, j, t}-\alpha_{l} l_{i, j, t}-\alpha_{k} k_{i, j, t}-\alpha_{m} m_{i, j, t}
$$

where the lower case letters $\{t f p, y, l, k, m\}$ indicate the logarithms of firm-level TFPR, output, labor employed, capital and materials. These are measured as deflated sales, number of employees, de-

\footnotetext{
${ }^{52}$ Levinsoh and Petrin require a competitive environment and that investment does not respond to current productivity. Melitz and Levinsohn (2006) show that the monotonicity condition holds in non-competitive environment as long as more productive firms does not charge inordinate larger markups than less productive firms.

${ }^{53}$ In practice, we approximate the unknown function $f_{t}^{-1}(\cdot)$ with a third-order polynomial in capital and intermediate inputs. This practice is common in Olley and Pakes (1996), Levinsohn and Petrin (2003) and in most of the literature that follow from thereafter.
} 
flated asset value and deflated total materials of company $i$ in industry $j$ at time $t .{ }^{54,55}$ To measure input elasticities $\alpha_{i}$, I use the average sectoral input cost share, of labor, capital and materials. ${ }^{56}$

Table 8: Regression - Age and average TFPR

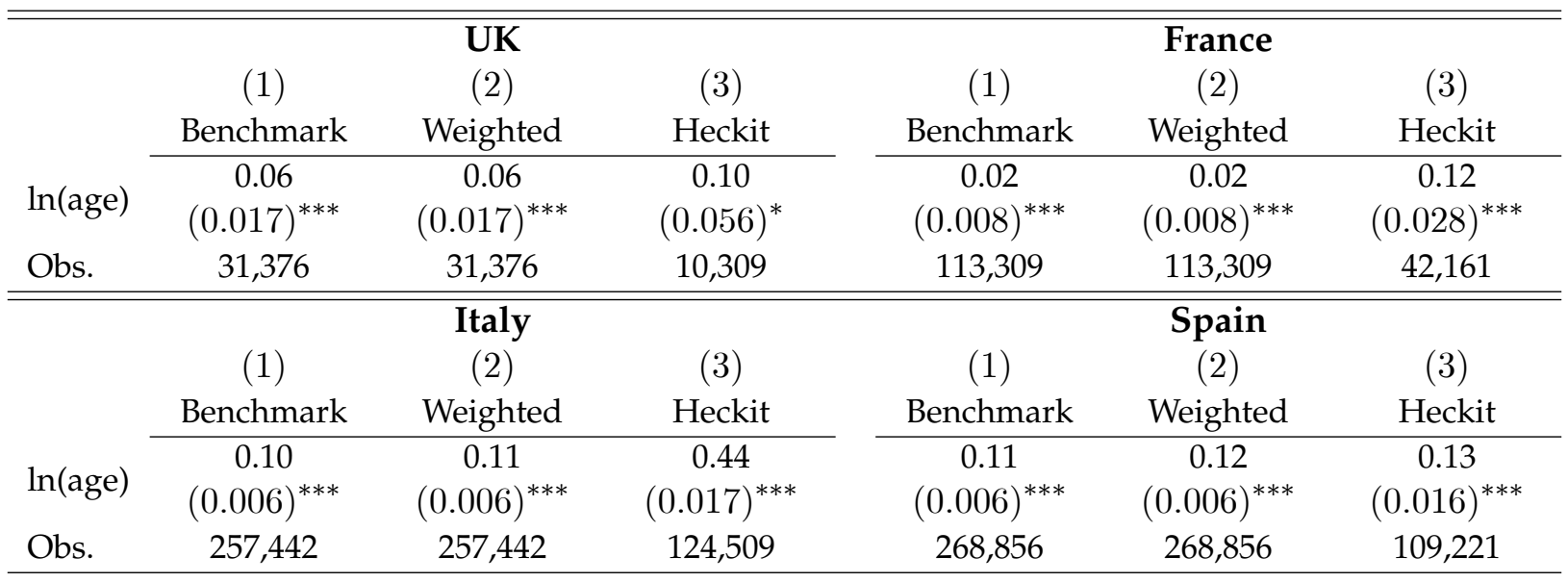

Note: This table presents the results of regressing the TFPR of a firm on its log-age for the 2006-2009 period. Firm TFPR was estimated using the Solow residual method proposed by Syverson (2004). All regressions have firm fixed-effects as well as industry-year fixed-effects. Weighted regressions use total real sales has a weight. Heckit regressions control for selection using the Heckman two-step procedure. Due to lower quality in the selection indicator, the Heckit regression uses a sample from 2007-2008. The probit regresses the selection indicator on the firm productivity, size and age.

\subsection{Data Cleaning Methodology}

In this section I describe in detail de procedure for the cleaning of the data. First, I require firms to have some basic accounting information over the years. Therefore, I drop firms that do not provide positive assets, sales, labor payments and liabilities, or that do not provide information on the age of the firm. ${ }^{57}$ Next, I delete from the sample, firms that report only consolidated statements, to avoid double counting firms and subsidiaries or operations abroad. I also exclude certain industries. I drop

\footnotetext{
${ }^{54}$ Sales, assets and material deflators were constructed using sectoral deflators, with sectors being defined at the two-digit NACE code.

${ }^{55} \mathrm{An}$ assumption of 13 is constant returns to scale. If the scale-elasticity is different from one we should multiply the input elasticities $\alpha$ by the firm-scale elasticity. To test the sensitivity of our results to this assumption, we reran our results assuming both increasing and decreasing returns to scale. Testing scale elasticities of 0.9 and 1.1. The qualitative results are maintained.

${ }^{56}$ The sectoral cost of capital used was obtained from the BLS. The assumption made was that the cost of capital is the same across economies. To test the sensitivity of our results to this assumption, we also calculated a country-specific sectoral cost of capital by multiplying the sectoral cost of capital provided by the BLS by a country-specific cost of capital. This country-specific cost of capital was obtained using the spread of a country's sovereign bonds with respect to the German ones in 2005.

${ }^{57}$ Less than 2 percent of the firms do not provide information regarding their age.
} 
Table 9: Regressions - Robustness Check with Alternative Definitions of Financial Development

\begin{tabular}{lcccccc}
\hline \hline & \multicolumn{2}{c}{ TFPR } & \multicolumn{2}{c}{ Growth } & \multicolumn{2}{c}{ Leverage } \\
& Fin. Dev. II & Fin. Dev. III & Fin Dev. II & Fin Dev. III & Fin. Dev. II & Fin. Dev. III \\
ln age & -0.04 & -0.05 & -0.04 & -0.09 & -0.06 & -0.06 \\
& $(0.002)^{* * *}$ & $(0.002)^{* * *}$ & $(0.002)^{* * *}$ & $(0.002)^{* * *}$ & $(0.001)^{* * *}$ & $(0.002)^{* * *}$ \\
$F D \times \ln$ age & 0.08 & 0.07 & 0.03 & 0.04 & 0.02 & 0.01 \\
Adj. $R^{2}$ & $(0.003)^{* * *}$ & $(0.002)^{* * *}$ & $(0.001)^{* * *}$ & $(0.002)^{* * *}$ & $(0.001)^{* * *}$ & $(0.001)^{* * *}$ \\
Obs. & 0.30 & 0.30 & & & & \\
\hline
\end{tabular}

Note: This table reports the coefficients of a series of regressions using two alternative definitions of financial development. Fin. Dev. II uses as a measure of financial development the ratio of private credit to total GCP whereas Fin. Dev. III uses as a measure of financial development the ratio of liquid liabilities to GDP. The three dependent variables are TFPR (revenueTFP), Growth (log-asset growth rate) and Leverage (ratio of total liabilities to total assets). All regressions have a fixed effect at the country-industry-year level. The standard errors reported in parentheses are robust to heteroskedasticity.

several primary sectors where the activity is very country-specific. These sectors include agriculture (NACE code 1), forestry (NACE code 2), fishing (NACE code 5), and mining (NACE codes 10-14). I also drop the financial services industries (NACE code 65-66) since the financial information for these firms is not-comparable to those of non-financial firms). Finally, I drop the public sector, education, health and social sector, and activities of organizations that cannot be classified (NACE code 75-99).

\subsection{Comparability of Country Samples}

This section analyzes the coverage of the Amadeus dataset across countries. The European Commission Report (ECR) contains information on the universe of firms per business sector for the majority of countries in the sample. The ECR reports the percentage of firms that have 1-49 employees, 50-249 employees and more than 250 employees. I compare the fraction of firms in each employment category with the ones present in Amadeus. Unfortunately, and as reported in Arellano, Bai, and Zhang (2012), employment information is not reported for all firms in Amadeus. On average, around 70\% of the firms in the cleaned sample report the number of employees, with the incidence of missing information being larger for small firms. To deal with this lack of employment information, I follow Arellano et al, and impute employment measures for firms that do not report employment in Amadeus. I run regressions country by country of $\log$ (employment) on $\log$ (assets) and $\log ($ sales $) .58$

\footnotetext{
${ }^{58}$ As referred above, I substitute operating revenue for sales for the Danish and Norwegian firms.
} 
Number of Firms per Age-Cohort

\begin{tabular}{|c|c|c|c|c|c|c|c|}
\hline \multirow[b]{3}{*}{ Country } & \multirow[b]{3}{*}{ Recovery Rate } & \multirow[b]{3}{*}{ No. Firms } & \multicolumn{5}{|c|}{ Share of Firms } \\
\hline & & & \multicolumn{5}{|c|}{ Age-Cohorts } \\
\hline & & & $<4$ & {$[4,7]$} & {$[8,11]$} & {$[12,18]$} & $18<$ \\
\hline Fin & 0.883 & 216,773 & 0.12 & 0.18 & 0.21 & 0.28 & 0.21 \\
\hline Ire & 0.877 & 38,204 & 0.25 & 0.29 & 0.17 & 0.17 & 0.12 \\
\hline Ned & 0.874 & 45,787 & 0.10 & 0.14 & 0.12 & 0.18 & 0.45 \\
\hline Nor & 0.944 & 432,793 & 0.22 & 0.25 & 0.16 & 0.38 & \\
\hline Bel & 0.86 & 974,593 & 0.18 & 0.20 & 0.16 & 0.26 & 0.20 \\
\hline UK & 0.86 & $1,139,416$ & 0.34 & 0.23 & 0.12 & 0.13 & 0.18 \\
\hline Ice & 0.82 & 39,271 & 0.36 & 0.27 & 0.13 & 0.11 & 0.12 \\
\hline Spn & 0.77 & $1,807,117$ & 0.22 & 0.26 & 0.21 & 0.20 & 0.11 \\
\hline Prt & 0.73 & 173,222 & 0.19 & 0.22 & 0.15 & 0.20 & 0.24 \\
\hline Swe & 0.81 & 565,565 & 0.15 & 0.15 & 0.16 & 0.29 & 0.24 \\
\hline Ita & 0.71 & $1,209,776$ & 0.21 & 0.22 & 0.14 & 0.19 & 0.24 \\
\hline Den & 0.63 & 165,227 & 0.30 & 0.28 & 0.10 & 0.17 & 0.16 \\
\hline Ger & 0.56 & 148,490 & 0.15 & 0.19 & 0.15 & 0.21 & 0.30 \\
\hline Lit & 0.34 & 15,998 & 0.20 & 0.29 & 0.36 & 0.14 & \\
\hline Fra & 0.46 & $2,436,583$ & 0.23 & 0.21 & 0.17 & 0.20 & 0.19 \\
\hline Gre & 0.45 & 71,390 & 0.19 & 0.22 & 0.18 & 0.22 & 0.19 \\
\hline Slk & 0.40 & 14,615 & 0.16 & 0.31 & 0.35 & 0.16 & 0.02 \\
\hline Hun & 0.39 & 350,581 & 0.33 & 0.25 & 0.26 & 0.15 & \\
\hline Est & 0.37 & 139,259 & 0.34 & 0.31 & 0.24 & 0.11 & 0.01 \\
\hline Lat & 0.36 & 13,298 & 0.17 & 0.29 & 0.38 & 0.16 & \\
\hline Bul & 0.34 & 15,475 & 0.19 & 0.25 & 0.27 & 0.17 & 0.12 \\
\hline Cro & 0.29 & 62,885 & 0.04 & 0.13 & 0.48 & 0.30 & 0.05 \\
\hline Pol & 0.26 & 68,339 & 0.13 & 0.24 & 0.24 & 0.24 & 0.15 \\
\hline Rus & 0.25 & 377,692 & 0.32 & 0.28 & 0.32 & 0.04 & 0.03 \\
\hline Srb & 0.21 & 49,513 & 0.06 & 0.16 & 0.39 & 0.33 & 0.06 \\
\hline Czh & 0.15 & 158,346 & 0.20 & 0.31 & 0.33 & 0.16 & 0.01 \\
\hline Ukr & 0.08 & 39,259 & 0.13 & 0.37 & 0.38 & 0.06 & 0.06 \\
\hline Rom & 0.07 & 774,217 & 0.30 & 0.20 & 0.33 & 0.17 & \\
\hline Total & 0.52 & $11,543,684$ & 0.21 & 0.24 & 0.24 & 0.19 & 0.14 \\
\hline
\end{tabular}

Table 10: Recovery rate is the average amount recouped by creditors of an insolvent firm, for each dollar of outstanding credit. The Number of firms is the total number of firm-year observations per country for 2002-2005. The Share of firms represents the fraction of firm-year observations per agecohort. The share of firms older than 18 years-old in Norway, Hungary, Latvia, Bulgaria and Romania is lower than 0.5 percent. 
Coverage and Cross-Country Comparability

\begin{tabular}{cccccccc}
\hline \hline & \multicolumn{3}{c}{ Amadeus Dataset } & & \multicolumn{3}{c}{ EC Data } \\
\cline { 2 - 4 } \cline { 7 - 8 } Country & $1-49$ & $50-250$ & $>250$ & & $1-49$ & $50-250$ & $>250$ \\
\hline Fin & 0.957 & 0.032 & 0.953 & 0.985 & 0.012 & 0.003 \\
Ire & 0.929 & 0.070 & 0.000 & & & \\
Ned & 0.610 & 0.309 & 0.072 & 0.981 & 0.016 & 0.003 \\
Nor & 0.975 & 0.020 & 0.004 & & & \\
Bel & 0.971 & 0.023 & 0.006 & & 0.009 & \\
UK & 0.907 & 0.071 & 0.020 & & 0.978 & 0.018 & 0.004 \\
Ice & 0.987 & 0.011 & 0.002 & & & \\
Spn & 0.962 & 0.031 & 0.006 & 0.991 & 0.008 & 0.001 \\
Prt & 0.929 & 0.061 & 0.010 & & & \\
Swe & 0.966 & 0.027 & 0.006 & & 0.990 & 0.008 & 0.002 \\
Ita & 0.944 & 0.047 & 0.008 & & 0.994 & 0.005 & 0.001 \\
Den & 0.950 & 0.041 & 0.008 & & & \\
Ger & 0.691 & 0.220 & 0.088 & & 0.972 & 0.023 & 0.005 \\
Lit & 0.711 & 0.225 & 0.039 & & 0.952 & 0.043 & 0.005 \\
Fra & 0.966 & 0.027 & 0.006 & & 0.987 & 0.010 & 0.003 \\
Gre & 0.894 & 0.078 & 0.014 & & & \\
Slk & 0.665 & 0.254 & 0.081 & & 0.931 & 0.055 & 0.014 \\
Est & 0.968 & 0.027 & 0.004 & & 0.966 & 0.030 & 0.004 \\
Hun & 0.982 & 0.015 & 0.002 & & & 0.001 \\
Lat & 0.731 & 0.211 & 0.053 & 0.970 & 0.027 & 0.003 \\
Bul & 0.683 & 0.217 & 0.094 & 0.982 & 0.016 & 0.002 \\
Cro & 0.905 & 0.072 & 0.021 & & & \\
Pol & 0.536 & 0.322 & 0.109 & 0.989 & 0.009 & 0.002 \\
Rus & 0.806 & 0.139 & 0.053 & & & \\
Srb & 0.856 & 0.099 & 0.043 & & & \\
Czh & 0.863 & 0.109 & 0.028 & & 0.991 & 0.008 & 0.001 \\
Ukr & 0.325 & 0.414 & 0.256 & & & \\
Rom & 0.972 & 0.022 & 0.005 & 0.971 & 0.023 & 0.006 \\
\hline
\end{tabular}

Table 11: The Amadeus dataset has the information used in the empirical exercises. The European Commission data, is obtained from the National Registrars and includes all formal firms within an economy 